\title{
Article \\ Study of the Effect of Vegetation on Reducing Atmospheric Pollution Particles
}

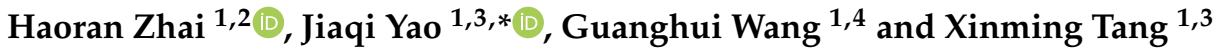 \\ 1 Land Satellite Remote Sensing Application Center, Ministry of Natural Resources, Beijing 100048, China; \\ 2@by2studio.cn (H.Z.); wanggh@lasac.cn (G.W.); txm@lasac.cn (X.T.) \\ 2 College of Resource Environment and Tourism, Capital Normal University, Beijing 100048, China \\ 3 College of Geomatics, Shandong University of Science and Technology, Qingdao 266590, China \\ 4 School of Environment and Spatial Informatics, China University of Mining and Technology, \\ Xuzhou 221116, China \\ * Correspondence: 201981020027@sdust.edu.cn
}

Citation: Zhai, H.; Yao, J.; Wang, G.; Tang, X. Study of the Effect of Vegetation on Reducing Atmospheric Pollution Particles. Remote Sens. 2022, 14, 1255. https://doi.org/ $10.3390 /$ rs 14051255

Academic Editor: Nancy Grulke

Received: 4 December 2021

Accepted: 1 March 2022

Published: 4 March 2022

Publisher's Note: MDPI stays neutral with regard to jurisdictional claims in published maps and institutional affiliations.

Copyright: (C) 2022 by the authors. Licensee MDPI, Basel, Switzerland. This article is an open access article distributed under the terms and conditions of the Creative Commons Attribution (CC BY) license (https:// creativecommons.org/licenses/by/ $4.0 /)$.

\begin{abstract}
Atmospheric particulate matter (PM) is a major air pollutant. $\mathrm{PM}_{2.5}$ and $\mathrm{PM}_{10}$ pose particularly serious threats to the ecological environment and human health. Vegetation plays an important role in reducing the concentration of particles. Based on a long time series of air quality, meteorological, and vegetation coverage data in the Beijing-Tianjin-Hebei (BTH) region, the present paper evaluated the influence at the overall and built-up area scales and quantified the process involved in the dry settlement of particles on vegetation based on a mathematical model. The experimental results showed that (1) the total amounts of $\mathrm{PM}_{10}$ reduced by vegetation in the BTH area were 505,200 t, 465,500 t, 477,200 $t$ and 396,500 $t$ in 2015, 2016, 2017 and 2018, respectively, and the total amount of $\mathrm{PM}_{2.5}$ was reduced by 19,400 t, 19,200 t, 16,400 $\mathrm{t}$ and 12,700 $\mathrm{t}$, respectively. The annual reduction in $\mathrm{PM}_{10}$ and $\mathrm{PM}_{2.5}$ from 2015 to 2018 by vegetation in the BTH region showed a downwards trend, and the annual reduction was mainly caused by the significant decrease in PM concentration. (2) More than $80 \%$ of the reduction in annual yield was concentrated in May-September, and a large leaf area was the main reason for the largest yield reduction in the growing season. The efficiency of PM reduction in forestland was approximately five-seven times that in grassland, and the deciduous broad-leaved forest was the main driver of this reduction in each forest. (3) The reduction in $\mathrm{PM}_{10}$ by vegetation was approximately 30 times that of $\mathrm{PM}_{2.5}$. However, the reduction in $\mathrm{PM}_{2.5}$ by vegetation should not be ignored because $\mathrm{PM}_{2.5}$ has a stronger correlation with human production and living activities. Increasing the area and density of green space via afforestation, returning farmland to forest and giving full play to the self-purification function of green spaces are very important to reducing and controlling the concentration of PM.
\end{abstract}

Keywords: $\mathrm{PM}_{2.5} ; \mathrm{PM}_{10}$; UFORE; air pollution; dust; LAI; remote sensing; China

\section{Introduction}

Air is indispensable to all human production and life. Breathing fresh air promotes human blood circulation and improves human immunity. Excessive particulate matter (PM) damages human respiratory, immune and blood circulation systems, leading to respiratory and cardiovascular diseases and death. Medical studies have consistently confirmed the serious impact of air pollution on human health and the importance of the quality of the atmospheric environment [1-3]. Air pollution is a worldwide public health problem and an environmental problem that has attracted the attention of academia and the public. Air pollution directly or indirectly changes ecosystem structure, diversity and stability; greatly affects human health, crop growth and road traffic; and seriously endangers normal social life [4,5]. Several studies have analyzed the relationship between PM concentrations and the incidence of heart and lung disease based on statistical data, and the results show 
positive correlations and that people's health will be greatly affected when they are exposed to high concentrations of PM [6-8].

Vegetation is the main component of terrestrial ecosystems, and it plays an important role in maintaining water and soil, regulating the atmosphere, slowing the increase in greenhouse gas concentrations and maintaining the entire ecosystem. Vegetation coverage has become an important part of the study of global environmental change, and it is of great value to geological, hydrological, meteorological and ecological changes [9-11]. To control the concentrations of PM in the atmosphere, various measures must be taken to reduce emissions and control the reduction of vegetation. Particles fall on vegetation, buildings, roads and bare ground via dry sedimentation, and vegetation intercepts and absorbs particles via retention, attachment and adhesion to leaves, stems and other organ structures [12,13]. Some differences exist in the PM retention effect between different vegetation types due to their different canopy structures, morphological characteristics and leaf roughness. The vegetation itself, its growth stage and its health level also affect PM retention ability [13-15]. Forestland, grassland and agricultural land are primarily covered by vegetation and effectively reduce the spread of PM $[16,17]$. Forests and grasslands are important components of ecosystems that have self-purification functions, which help improve environmental quality, regulate ecological balance, protect human health and play an important role in beautifying urban landscapes $[18,19]$. Studies indicate that native plants and green belt projects also contribute to reducing the annual rates of PM by $68.4 \%$ in western parts of Asia [20,21]. Escobedo et al. found that high vegetation coverage will increase the amount of PM in the area [22]. Vos et al. proved that the improvement effect of green space on air quality is positively correlated with canopy closure and negatively correlated with porosity [23]. Zhang et al. confirmed that the increase in PM retention benefits of shelterbelts in the Three Norths of China is closely related to the increase in the leaf area index (LAI) [24]. Al-Dousari et al. indicated that forestation is likely to exacerbate drought and could also increase air pollutants, which was indicated by a 9.9\% lower pollen content within trapped aeolian deposits in 2010-2011 than in 2009$2010[25,26]$. Therefore, exploring the relationship between vegetation coverage and PM pollution using scientific experiments and quantitative evaluation of the effect of vegetation on PM reduction will provide powerful references for regional development and scientific and rational suggestions for urban greening.

Dry deposition is an important way for vegetation to reduce PM, and its process is difficult to accurately quantify using simple mathematical relationships. Previous studies focused more on differences in the PM retention abilities of different leaves and tree species and compared differences in the PM retention abilities of different stands on a small scale. These studies proposed reasonable suggestions for regional garden and green space planning via comparisons of the results, but few studies quantified the reduction effect of vegetation on PM on a large scale. The present study chose the Beijing-Tianjin-Hebei (BTH) region because atmospheric particulate pollution is frequent and serious. The urban forest effects (UFORE) model was used to quantify the vegetation dry subsidence process using the measured data of air quality monitoring stations and multisource satellite data. The reduction effect of vegetation on $\mathrm{PM}_{2.5}$ and $\mathrm{PM}_{10}$ in the $\mathrm{BTH}$ region was estimated on the scale of the entire city and the built-up area. The research conclusions provide a scientific basis and theoretical reference for air pollution prevention, regional land planning and urban greening.

\section{Materials and Methods}

\subsection{Overview of the Study Area}

The BTH region is located in North China (Figure 1). The terrain is inclined, high in the northwest and low in the southeast, with complex and changeable landforms, including plateaus, mountains, hills, basins and plains. From northwest to southeast, the region is roughly divided into the Bashang Plateau, the Yanshan-Taihang Mountains and the Haihe Plain. The BTH region has a temperate semihumid continental monsoon climate, with 
distinct winters and summers, with different conditions in the mornings and evenings, and greater than $67 \%$ of precipitation is concentrated in the summer. The BTH region covers an area of approximately 217,200 square kilometres, which accounts for $2.3 \%$ of China. This area has a dynamic economy, the highest degree of economic openness, the strongest innovation ability and the largest foreign population in China. However, many PM indicators seriously exceed the standards due to the dense population and industrial agglomerations, smog and other air pollution phenomena that frequently occur in the BTH region with the rapid development of the economy. Air pollution seriously threatens the ecological environment and human health and affects the quality of life of residents. The pollution situation in the BTH region is the most representative in China and the world.

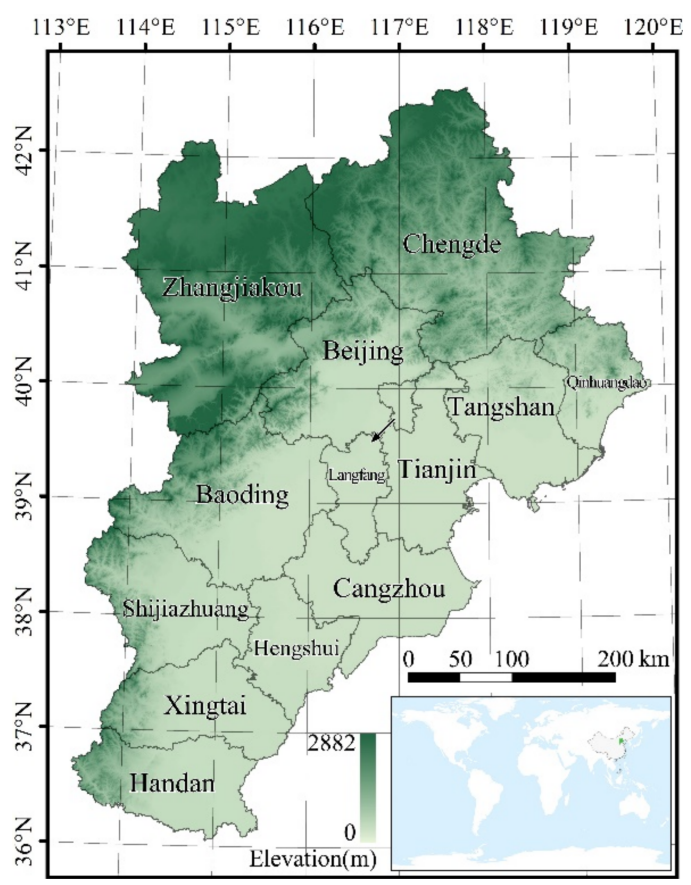

Figure 1. Geographical location $\left(113^{\circ} 27^{\prime}-119^{\circ} 51^{\prime} \mathrm{E}, 36^{\circ} 05^{\prime}-42^{\circ} 40^{\prime} \mathrm{N}\right)$ of the study area.

\subsection{PM Reduction}

The reduction effect of vegetation on PM is generally obtained by calculating the amount of dust retention of vegetation and its economic benefits in designated areas, and quantitative analysis by modelling is the most commonly used method [14,19,27]. In this paper, the variation in PM concentration is quantified using the data provided by the BTH regional ground air quality monitoring station. Scholars established scientific models based on different methods and attempted to quantify the dust retention of vegetation. The UFORE model is widely recognized [16]. The UFORE model was produced in the 1990s and developed by the Northeast Forest Research Center of the United States Department of Agriculture (USDA). This model is widely used in research in many parts of the world. The UFORE model can be applied to landscape and regional scales at the stand sample scale and urban and nonurban areas at any scale. It quantitatively evaluates the structure and function of urban forests and green spaces, and it was determined as an authoritative forest benefit evaluation model in recent years $[14,16]$

The UFORE-D model is a submodel that is used to calculate the dry sedimentation process of forest particles. It can be used to estimate the dry deposition of $\mathrm{O}_{3}, \mathrm{NO}_{2}, \mathrm{SO}_{2}$, $\mathrm{CO}, \mathrm{PM}_{10}$ and $\mathrm{PM}_{2.5}$ during a certain time and over a certain range and the corresponding percentage of air quality improvement. The current experiment used the core method of the UFORE-D model to estimate the reduction in $\mathrm{PM}_{2.5}$ and $\mathrm{PM}_{10}$ by forestland and grassland in the BTH region from 2015 to 2018. The reduction in PM was calculated as the cumulative 
temporal value of the product of dry deposition flux and the total area of vegetation leaves in the region using the following formula:

$$
P=\sum_{t=1}^{n} F l u x_{t} \cdot L A I_{t} \cdot S V .
$$

where $p$ represents the reduction in PM, Flux $x_{t}$ represents the dry sedimentation flux of PM per unit area at time $t, L A I_{t}$ represents the LAI value at time $t$ and $S V$ represents the vegetation coverage area. As the $L A I_{t}$ and $S V$ values were extracted from remote sensing data, the dry deposition flux is the key to calculating the reduction in PM.

\subsection{Leaf Area Index and Vegetation Coverage Area}

LAI is defined as the unilateral green leaf area per unit ground area in a broadleaf canopy and one-half of the total needle surface area per unit ground area in a coniferous canopy $[28,29]$. LAI is related to the density and structure of vegetation, the biological characteristics of trees and environmental conditions. It comprehensively represents the utilization of light energy and the canopy structure of vegetation. Based on the MODIS global LAI/FPAR product MCD15A3H with a spatial resolution of $500 \mathrm{~m}$, the LAI values of vegetation types in each region were obtained, and the temporal resolution of the data was 4 days. The LAI values of vegetation types in each region were extracted from each dataset as the LAI values of the entire city of the current day and the next 3 days. For the built-up area scale, the LAI value at the whole-city scale was used for calculation because some MCD15A3H data were missing in the built-up area. The LAI values of forestland types were the area-weighted average of LAI values of evergreen coniferous forest (ECF), deciduous, coniferous forest (DCF) and deciduous broad-leaved forest (DBF), and the LAI values of shrubland and grassland were used separately on the whole-city scale.

The land use/land cover data used in the experiment included the MODIS land cover type product MCD12Q1 with a spatial resolution of $500 \mathrm{~m}$ and finger resolution observation and monitoring of global land cover (FROM-GLC) data with a spatial resolution of $10 \mathrm{~m}$. On the whole-city scale, the annual areas of ECF, DCF, DBF and shrubland were extracted based on MCD12Q1 data, and the coverage rate of each vegetation type in each city was calculated according to the total area of each city. On the scale of the built-up area, the overall scope of each city's built-up area was extracted according to MCD12Q1 data, and then the areas of forestland, shrubland and grassland in each city's built-up area were extracted based on FROM-GLC land use data with a $10 \mathrm{~m}$ spatial resolution.

\subsection{Dry Sedimentation Rate and Resuspension Rate}

The dry deposition of forests was taken into account first. According to the results for $\mathrm{PM}_{10}$ in references [30,31], $V_{d}$ was set to $0.0064 \mathrm{~m} \cdot \mathrm{s}^{-1}$ when the LAI value was 6 . The $V_{d}$ value was adjusted in the experiment according to the actual LAI value and leaf growth condition and was calculated using the following formula [32]:

$$
V_{d}=V_{d, P M 10} \frac{(B A I+L A I)}{\left(B A I+L A I_{P M 10}\right)}
$$

where $V_{d, P M 10}$ is $0.0064 \mathrm{~m} \cdot \mathrm{s}^{-1}, B A I$ is the bark area index of $1.7, \mathrm{LAI}$ is the leaf area index and $L A I_{P M 10}$ is the leaf area index of 6.0 based on the literature $[30,31]$ under experimental conditions. Therefore, the dry sedimentation rate of $\mathrm{PM}_{10}$ was primarily related to the LAI $[11,33]$. Since the diameter and mass of $\mathrm{PM}_{10}$ are much larger than those of $\mathrm{PM}_{2.5}$, the resuspension of $\mathrm{PM}_{10}$ is generally not considered in the calculation process.

For $\mathrm{PM}_{2.5}$, the dry settlement rate of the leaf surface is the reciprocal of the sum of the migration resistance of particles from the leaf surface to the interior and was calculated using the following formula [34]:

$$
V_{d}=\left(R_{a}+R_{b}+R_{c}\right)-1
$$


where $R_{a}$ is the aerodynamic resistance, $R_{b}$ is the turbulent boundary layer resistance and $R_{c}$ is the canopy resistance, all in $\mathrm{m} \cdot \mathrm{s}^{-1}$. The following formulas were used:

$$
\begin{gathered}
R_{a}=u(z) / u_{*}^{2} \\
R_{b}=2(S c)^{2 / 3}(P r)^{-2 / 3}\left(k u_{*}\right)^{-1} \\
R_{c}=\left(\left(r_{s}+r_{m}\right)^{-1}+r_{t}^{-1}+r_{\text {soil }}{ }^{-1}\right)^{-1}
\end{gathered}
$$

where $u$ is the wind speed, $u *$ is the friction velocity, $S_{c}$ is the Schmidt number, $\operatorname{Pr}$ is the Prandtl number, $k$ is the von Karman constant, $0.4, r_{S}$ is the stomatal resistance, $r_{m}$ is the mesophyll resistance, $r_{t}$ is the stomatal resistance and $r_{\text {soil }}$ is the soil resistance $[19,35,36]$. $R_{a}$ and $R_{b}$ are primarily related to wind speed, and forest removal of PM was not directly related to transpiration.

For $\mathrm{PM}_{2.5}$, the dry settling rate of $\mathrm{PM}_{2.5}$ was greatly affected by wind speed, and the $V_{d}$ value was generally based on the results of literature research. References [37-39] measured the dry sedimentation rate of $\mathrm{PM}_{2.5}$ of 17 types of trees at wind speeds of $1,3,6$, 8.5 and $10 \mathrm{~m} \cdot \mathrm{s}^{-1}$, as shown in Table 1 . The $V_{d}$ of wind speed was estimated for each speed using the median deposition speed measured in the literature, and the nearest measured value was interpolated to obtain the deposition speed that corresponded to the unmeasured wind speed, as shown in Table 2 [37-39]. Statistics revealed that the maximum hourly wind speed of each city in the study area from 2015 to 2018 did not exceed $13 \mathrm{~m} \cdot \mathrm{s}^{-1}$. Therefore,

\begin{tabular}{|c|c|c|c|c|c|}
\hline \multirow{2}{*}{ Varieties of Trees } & \multicolumn{5}{|c|}{ Wind Speed $\left(\mathrm{m} \cdot \mathrm{s}^{-1}\right)$} \\
\hline & 1 & 3 & 6 & $8.5^{\mathrm{a}}$ & 10 \\
\hline Quercus petraea [37] & & 0.00831 & 0.01757 & 0.03134 & \\
\hline Alnus glutinosa [37] & & 0.00125 & 0.00173 & 0.00798 & \\
\hline Fraxinus excelsior [37] & & 0.00178 & 0.00383 & 0.00725 & \\
\hline Acer pseudoplatanus [37] & & 0.00042 & 0.00197 & 0.00344 & \\
\hline Psuedotsuga menziesii [37] & & 0.01269 & 0.01604 & 0.0604 & \\
\hline Eucalyptus globulus [37] & & 0.00018 & 0.00029 & 0.00082 & \\
\hline Ficus nitida [37] & & 0.00041 & 0.00098 & 0.00234 & \\
\hline Pinus nigra $[38]$ & 0.0013 & 0.0115 & & 0.1924 & 0.2805 \\
\hline Cupressocyparis $\times$ leylandii $[38]$ & 0.0008 & 0.0076 & & 0.0824 & 0.122 \\
\hline Acer campestre $[38]$ & 0.0003 & 0.0008 & & 0.0046 & 0.0057 \\
\hline Sorbus intermedia [38] & 0.0004 & 0.0039 & & 0.0182 & 0.0211 \\
\hline Populus deltoides [38] & 0.0003 & 0.0012 & & 0.0105 & 0.0118 \\
\hline Pinus strobus [39] & 0.000108 & & & & \\
\hline Tsuga canadensis [39] & 0.000193 & & & & \\
\hline Tsuga japonica [39] & 0.000058 & & & & \\
\hline Maximum value for Picea abies b [39] & 0.000189 & & & & \\
\hline Minimum value for Picea abies ${ }^{\text {b }}$ [39] & 0.00038 & & & & \\
\hline Median & 0.0003 & 0.00152 & 0.00197 & 0.00924 & 0.0211 \\
\hline Standard error & 0.00012 & 0.00133 & 0.00281 & 0.0161 & 0.05257 \\
\hline Maximum $^{\mathrm{c}}$ & 0.00057 & 0.00442 & 0.00862 & 0.05063 & 0.14542 \\
\hline Minimum $^{\mathrm{d}}$ & 0.00006 & 0.00018 & 0.00029 & 0.00082 & 0.0057 \\
\hline
\end{tabular}
wind speeds greater than $13 \mathrm{~m} \cdot \mathrm{s}^{-1}$ were not considered.

Table 1. Deposition velocity $\left(\mathrm{m} \cdot \mathrm{s}^{-1}\right)$ of $\mathrm{PM}_{2.5}$ by wind speed per unit leaf area (taken from [37-39]).

a Combination of $8 \mathrm{~m} \cdot \mathrm{s}^{-1}$ and $9 \mathrm{~m} \cdot \mathrm{s}^{-1}$ wind speed. ${ }^{b}$ Based on maximum and minimum of reported range. Included particles up to $3.8 \mu \mathrm{m}$ in diameter. ${ }^{\mathrm{c}}$ Based on 95 percent confidence interval above median value. ${ }^{\mathrm{d}}$ Based on lowest recorded for any species.

Since $\mathrm{PM}_{2.5}$ is generally composed of very fine particles, at a certain wind speed, some of the $\mathrm{PM}_{2.5}$ that has settled on the surface of vegetation will be resuspended into the atmosphere. The amount of resuspension should be considered when calculating $\mathrm{PM}_{2.5}$. Resuspension refers to the process of dry settling particles attached to the plant surface and returning to the atmosphere, and its proportion is related to wind power. One reference [39] estimated the variation in the $\mathrm{PM}_{2.5}$ resuspension rate in trees with wind speed and measured the resuspension rate of $\mathrm{PM}_{2.5}$ in leaves of three types of trees at wind speeds 
of $6.5,10$ and $13 \mathrm{~m} \cdot \mathrm{s}^{-1}$. The resuspension rate is generally assumed to be $0 \%$ when the wind speed is $0 \mathrm{~m} \cdot \mathrm{s}^{-1}$, and the resuspension rate corresponding to the unmeasured wind speed can be obtained via interpolation with the nearest measured value. When the wind speed was greater than $13 \mathrm{~m} \cdot \mathrm{s}^{-1}$, the resuspension rate at $13 \mathrm{~m} \cdot \mathrm{s}^{-1}$ was used, as shown in Table 2 [37-39]. The wind speed and precipitation data used in the experiment came from the global meteorological data provided by the National Environmental Information Center (NCEI). A total of 18 meteorological monitoring stations located in the study area were selected for the experiment. If one or more monitoring stations were located in a city, the arithmetic average value of the monitoring station was used to represent the city; if no stations were located in a certain area, the arithmetic average value of several adjacent cities was used.

Table 2. Deposition velocities and resuspension rates (taken from [39]). of $\mathrm{PM}_{2.5}$ by wind speed per unit leaf area.

\begin{tabular}{|c|c|c|}
\hline Wind Speed $\left(\mathrm{m} \cdot \mathrm{s}^{-1}\right)$ & Deposition Velocity $\left(\mathrm{m} \cdot \mathrm{s}^{-1}\right)$ & Resuspension Rate [39] \\
\hline 1 & 0.0003 & 0.015 \\
\hline 2 & 0.0009 & 0.030 \\
\hline 3 & 0.0015 & 0.045 \\
\hline 4 & 0.0017 & 0.060 \\
\hline 5 & 0.0019 & 0.075 \\
\hline 6 & 0.0020 & 0.090 \\
\hline 7 & 0.0056 & 0.100 \\
\hline 8 & 0.0092 & 0.110 \\
\hline 9 & 0.0092 & 0.120 \\
\hline 10 & 0.0211 & 0.130 \\
\hline 11 & 0.0211 & 0.160 \\
\hline 12 & 0.0211 & 0.200 \\
\hline
\end{tabular}

Few direct studies on the dry deposition rate of grassland PM were conducted, but some studies compared the reduction efficiency of forestland and grassland PM. The observations and predictions of Shreffler et al. [40,41] showed that the deposition rate in forests was 2-3 times the rate in grassland, and Fowler et al. [11,42,43] demonstrated that the dry deposition rate in forestland was approximately 3 times the rate in grassland. Therefore, the dry deposition rate of grassland in the current experiment was set to $1 / 3$ of that of forestland under the same environment.

\subsection{Dry Sedimentation Flux}

The dry sedimentation flux represents the dry settling amount of PM per unit area per unit time, and it is the product of the dry sedimentation rate and PM concentration. The dry settling flux occurring at time $t$ was calculated as follows:

$$
\text { flux }_{t}=V_{d} \cdot C \cdot 3600 \mathrm{~s} \text {. }
$$

where $\mathrm{flux}_{t}$ represents the dry sedimentation flux per square metre per hour in $\mathrm{g} \cdot \mathrm{m}^{-2} \cdot \mathrm{h}^{-1}$, $V_{d}$ represents the dry settlement rate of the blade surface in $\mathrm{m} \cdot \mathrm{s}^{-1}$ and $C$ represents the concentration of $\mathrm{PM}$ in $\mathrm{g} \cdot \mathrm{m}^{-3} \cdot \mathrm{h}^{-1}$. The PM concentration data used in the experiment were real-time monitoring data from the monitoring stations, which came from the national urban air quality real-time publishing platform of the China National Environmental Monitoring Station (http://106.37.208.233:20035/) (accessed on 1 December 2021). A total of 78 stations are located in the study area, and each station measures the hourly concentrations of $\mathrm{PM}_{2.5}, \mathrm{PM}_{10}, \mathrm{PM}, \mathrm{SO}_{2}, \mathrm{NO}_{2}, \mathrm{CO}, \mathrm{O}_{3}$, etc.

The amount of resuspension should be considered when calculating $\mathrm{PM}_{2.5}$. If no precipitation occurs, the settled particles accumulate on the blades over time and return to the atmosphere at the resuspension speed of the amount accumulated at that time. The resuspension amount at time $t$ is the sum of the accumulated PM amount on the blade at 
time $\mathrm{t}^{-1}$ and the dry sedimentation amount at time $t$ multiplied by the resuspension rate, and it was calculated as follows:

$$
R_{t}=\left(A c c_{t-1}+f l u x_{t}\right) \cdot r r_{t} / 100
$$

where $R_{t}$ is the amount of air resuspended at time $t$ in $\mathrm{g} \cdot \mathrm{m}^{-2} \cdot \mathrm{h}^{-1}, A c c_{t-1}$ is the amount of PM accumulated on the blade at $\mathrm{t}^{-1}$ in $\mathrm{g} \cdot \mathrm{m}^{-2} \cdot \mathrm{h}^{-1}$ and $r r_{t}$ is the resuspension rate at time $t$. When resuspension occurs, the accumulated amount of particles on the blade was calculated as follows:

$$
A c c_{t}=\left(A c c_{t-1}+f l u x_{t}\right)-R_{t}
$$

where $A c c_{t}$ is the amount of PM accumulated on the leaves at time $t$, with the unit of $\mathrm{g} \cdot \mathrm{m}^{-2} \cdot \mathrm{h}^{-1}$. Therefore, the net flux at time $t$ is the difference between the dry sedimentation flux and resuspension amount, and it was calculated as follows:

$$
\text { Flux }_{t}=\text { flux }_{t}-R_{t}
$$

where Flux $x_{t}$ is the net flux per unit area at time $t$, i.e., the amount of PM reduced by vegetation in units of $\mathrm{g} \cdot \mathrm{m}^{-2} \cdot \mathrm{h}^{-1}$. When the net flux is negative due to excessive resuspension and the absolute value of the net flux per unit area is greater than the total amount of PM per unit area of the atmosphere (Mtotal), the net flux is adjusted to $M_{\text {total }} . M_{\text {total }}$ was calculated as follows:

$$
M_{\text {total }}=C \cdot M L H
$$

where $M_{\text {total }}$ is the total amount of PM in the air per unit area in $\mathrm{g} \cdot \mathrm{m}^{-2} \cdot \mathrm{h}^{-1}, C$ is the concentration of PM per hour in $\mathrm{g} \cdot \mathrm{m}^{-3} \cdot \mathrm{h}^{-1}$ and $M L H$ is the height of the mixed layer in metres. The heights of the mixed layers in the study area in spring, summer, autumn and winter were $700 \mathrm{~m}, 620 \mathrm{~m}, 500 \mathrm{~m}$ and $480 \mathrm{~m}$, respectively [44].

When precipitation occurred, particles that accumulated on the blades or were washed to the ground were determined. According to the literature reports, leaves capture approximately $0.2 \mathrm{~mm}$ of precipitation. Therefore, the total precipitation storage capacity of the canopy was calculated as follows [45]:

$$
P_{S}=0.2 \cdot L A I
$$

where $P_{S}$ is the total rainfall storage capacity of the canopy in $\mathrm{mm}$. When the precipitation accumulation reaches $P_{S}$, the particles accumulated on the leaf surface are assumed to flow to the surface from the leaves, and the resuspension amount declines to zero. When the precipitation is less than $P_{s}$, the assumption is that no particles flow down from the leaves. When the precipitation stops, the particles begin to accumulate again, and resuspension begins to recur. The accumulated moisture on the blade evaporates back into the air each hour according to the evaporation speed. The total amount of annual sedimentation can be calculated as the sum of the number of particles flowing to the ground from the leaf surface and the number of particles remaining on the leaf surface at the end of the year.

\subsection{Assessment of Air Quality Improvement Effect}

Due to dry sedimentation, the hourly air quality improvement rate per unit area in the vegetation-covered area was calculated as follows:

$$
\begin{aligned}
& I_{\text {unit }}= \text { Flux }_{t} /\left(\text { Flux }_{t}+M_{\text {total }}\right) \cdot 100, \text { Flux } \\
& I_{\text {unit }}=\text { Flux } \\
& \text { t }
\end{aligned}
$$

where $I_{\text {unit }}$ is the air quality improvement rate of the vegetation coverage area per unit area, Flux $x_{t}$ is the net flux of PM per unit area in $\mathrm{g} \cdot \mathrm{m}^{-2} \cdot \mathrm{h}^{-1}$ and $M_{\text {total }}$ is the total amount 
of PM in the air per unit area in $\mathrm{g} \cdot \mathrm{m}^{-2} \cdot \mathrm{h}^{-1}$. For the entire region, the hourly air quality improvement was calculated as follows:

$$
\begin{aligned}
& I_{\text {total }}= \text { Flux }_{t} \cdot S_{v} /\left(\text { Flux }_{t} \cdot S_{v}+M_{\text {total }} \cdot S_{\text {region }}\right) \cdot 100, \text { Flux } \\
& \\
& I_{\text {total }}=\text { Flux }_{t} \cdot S_{v} /\left(M_{\text {total }}, \cdot, S_{\text {region }}\right) \cdot 100, \text { Flux } \\
& \text { t }
\end{aligned}
$$

where the improvement rate of air quality per unit area of the entire district is in $\%, S V$ is the area covered by vegetation in $\mathrm{m}^{2}$ and $S_{\text {region }}$ is the area of the entire area represented by $\mathrm{m}^{2}$. The variation in PM concentration caused by dry sedimentation was calculated as follows:

$$
\Delta C=C \cdot\left(\left(1-I_{\text {total }} / 100\right)^{-1}-1\right)
$$

where $\Delta C$ represents the hourly PM concentration change caused by dry sedimentation in $\mathrm{g} \cdot \mathrm{m}^{-3} \cdot \mathrm{h}^{-1}$ and $C$ is the hourly PM concentration measured by the air quality monitoring station.

\section{Experiment}

\subsection{Temporal and Spatial Distribution Analysis of PM Concentration}

The monthly average concentrations of PM in each city obtained from hourly data of the air quality monitoring station are shown in Figure 2. Similar to the previous analysis results, the concentration of $\mathrm{PM}_{2.5}$ in winter was obviously higher than that in summer, and the concentrations in spring and autumn were similar and between those of winter and summer. The concentrations of $\mathrm{PM}_{10}$ were generally winter > spring > autumn > summer. The highest $\mathrm{PM}_{2.5}$ and $\mathrm{PM}_{10}$ values appeared in December 2015 and were $135.7 \mu \mathrm{g} \cdot \mathrm{m}^{-3}$ and $199.3 \mu \mathrm{g} \cdot \mathrm{m}^{-3}$, respectively. The lowest values appeared in September and August 2018, at $27.9 \mu \mathrm{g} \cdot \mathrm{m}^{-3}$ and $57.6 \mu \mathrm{g} \cdot \mathrm{m}^{-3}$, respectively. The ratio of $\mathrm{PM}_{2.5}$ to $\mathrm{PM}_{10}$ fluctuated between $30 \%$ and $70 \%$, and two peaks occurred near July and December in each year. The maximum value was 68.1\% in December 2015, and the minimum value was 33.2\% in May 2017.

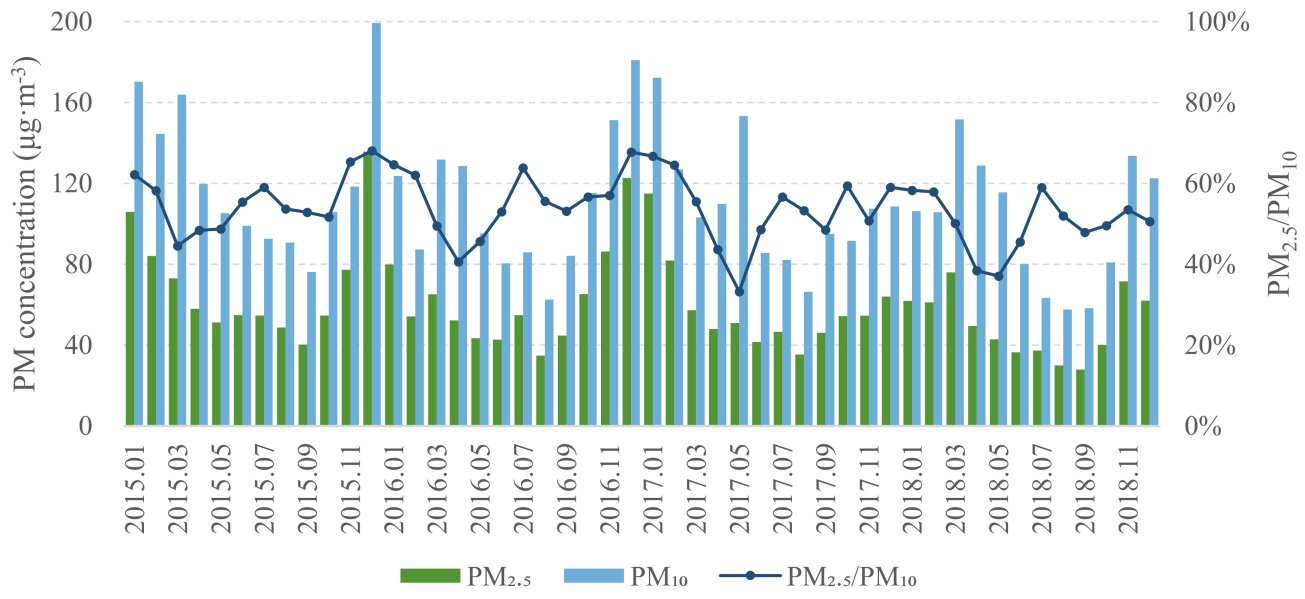

Figure 2. Variation trend of the monthly mean PM concentration in the BTH region from 2015 to 2018.

The China Environmental Air Quality Index (AQI) Technical Regulations (HJ633-2012) stipulate that air quality can be divided into six levels. To characterize the changes more intuitively, the AQI value of the six levels is translated into $\mathrm{PM}_{2.5}$ and $\mathrm{PM}_{10}$ concentrations according to the AQI formula, and the concentrations of PM are divided as follows: a $\mathrm{PM}_{2.5}$ concentration of $0-35 \mu \mathrm{g} \cdot \mathrm{m}^{-3}$ is excellent; $35-75 \mu \mathrm{g} \cdot \mathrm{m}^{-3}$ is good; $75-115 \mu \mathrm{g} \cdot \mathrm{m}^{-3}$ is light pollution; $115-150 \mu \mathrm{g} \cdot \mathrm{m}^{-3}$ is moderate pollution; $150-250 \mu \mathrm{g} \cdot \mathrm{m}^{-3}$ is heavy pollution; and greater than $250 \mu \mathrm{g} \cdot \mathrm{m}^{-3}$ is serious pollution. A $\mathrm{PM}_{10}$ concentration of $0-50 \mu \mathrm{g} \cdot \mathrm{m}^{-3}$ is excellent; $50-150 \mu \mathrm{g} \cdot \mathrm{m}^{-3}$ is good; $150-250 \mu \mathrm{g} \cdot \mathrm{m}^{-3}$ is light pollution; $250-350 \mu \mathrm{g} \cdot \mathrm{m}^{-3}$ is moderate pollution; $350-420 \mu \mathrm{g} \cdot \mathrm{m}^{-3}$ is heavy pollution; and greater than $420 \mu \mathrm{g} \cdot \mathrm{m}^{-3}$ is serious pollution. The daily average concentrations of PM in the BTH region from 2015 
to 2018 are shown in Figure 3. From 2015 to 2018, excellent and good $\mathrm{PM}_{2.5}$ grades were observed on days 245, 271, 294 and 309, which showed gradually increasing trend, and the number of days in which air quality grades reached the standard increased annually. Light pollution was observed on days 70,59, 42 and 38, and moderate pollution was observed on days 31, 20, 14 and 15. Heavy pollution was observed on days 17, 14, 15 and 3, and severe pollution was observed on days 2, 2, 0 and 0 . All pollution levels exhibited a downwards trend. Excellent and good days of $\mathrm{PM}_{10}$ occurred on days 266, 288, 314 and 308, increasing annually from 2015 to 2017 . Although the number of days that reached the standard in 2018 was slightly less than that in 2017, the number of days with good air quality increased annually. Light pollution occurred on days 82, 67, 42 and 50, and moderate and above pollution were observed on days 17,11,9 and 7. The number of days of mild and moderate pollution generally decreased.

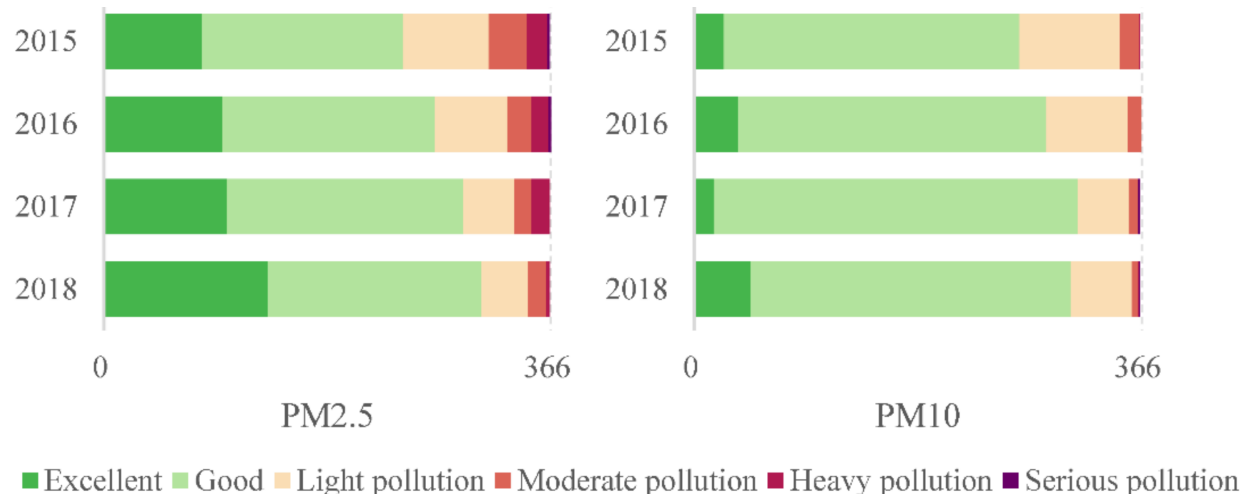

Figure 3. Daily count of daily average PM concentration in different grades from 2015 to 2018.

The daily average particle concentrations in the BTH region were calculated from 2015 to 2018. Red indicates a high concentration, and green and blue indicate a low concentration. The results are shown in Figures 4 and 5. The daily average value was higher in winter, and a large difference occurred between daily concentrations. The concentration was generally low in summer when small fluctuations and relatively stable concentrations were observed [46]. The daily average concentrations on 4 May 2017, 5 May 2017, 28 March 2018 and 26 November 2018 were significantly higher than those in other years, and the first three days were primarily in spring. The vegetation coverage rate was low, and severe sandstorms occurred in most of the study areas. On the fourth day, severe haze appeared in most areas of the study area due to the heating period in winter and the meteorological conditions that were unfavourable to the diffusion of particulates.

\subsection{Analysis of Environmental Elements \\ 3.2.1. Meteorological Factors}

The monthly average wind speed in the study area was evaluated from hourly data, and the results are shown in Figure 6. The wind speed was low in January each year, approximately $2.50 \mathrm{~m} \cdot \mathrm{s}^{-1}$. The monthly average wind speed gradually increased and reached a maximum value of $3.05 \mathrm{~m} \cdot \mathrm{s}^{-1}$ in May. The wind speed gradually decreased from May to August and reached a minimum value of $2.17 \mathrm{~m} \cdot \mathrm{s}^{-1}$ in August. The wind speed was stable from August to December. The annual average wind speeds in the study area in $2015,2016,2017$ and 2018 were $2.46 \mathrm{~m} \cdot \mathrm{s}^{-1}, \mathrm{~m} \cdot \mathrm{s}^{-1}, 2.53 \mathrm{~m} \cdot \mathrm{s}^{-1}$ and $2.52 \mathrm{~m} \cdot \mathrm{s}^{-1}$, respectively.

BTH has a temperate semihumid continental monsoon climate with great differences among the four seasons, and precipitation is primarily concentrated in summer. Monthly precipitation in the study area was calculated, and the results are shown in Figure 6. The monthly average precipitation in the study area had obvious periodicity, with $68.9 \%$ of precipitation concentrated in summer, $12.0 \%$ concentrated in spring, $17.2 \%$ concentrated in autumn and only $1.9 \%$ concentrated in winter. The average monthly precipitation in July was the highest for the entire year, and the average monthly precipitation in December was 
only $1.7 \mathrm{~mm}$. Precipitation reached a peak of $268.6 \mathrm{~mm}$ in July 2016, and only $0.2 \mathrm{~mm}$ was observed in December 2017. Some cities received no precipitation for an entire month. The annual precipitation in the study area in 2015, 2016, 2017 and 2018 was $505.5 \mathrm{~mm}, 639.3 \mathrm{~mm}$, $518.2 \mathrm{~mm}$ and $510.3 \mathrm{~mm}$, respectively, and the precipitation in 2016 was obviously higher than that in the other years.

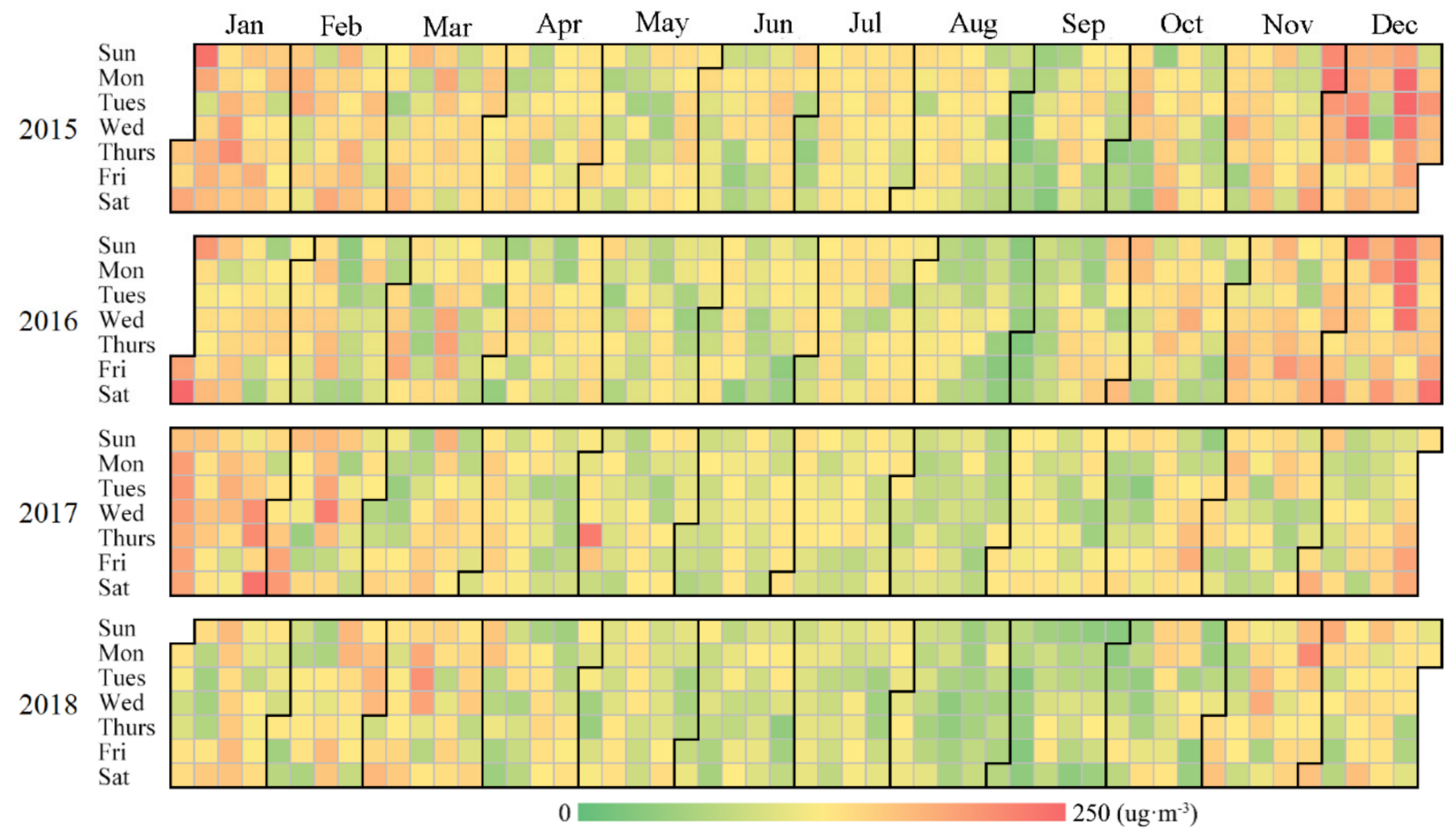

Figure 4. Thermographic calendar of daily $\mathrm{PM}_{2.5}$ concentration.

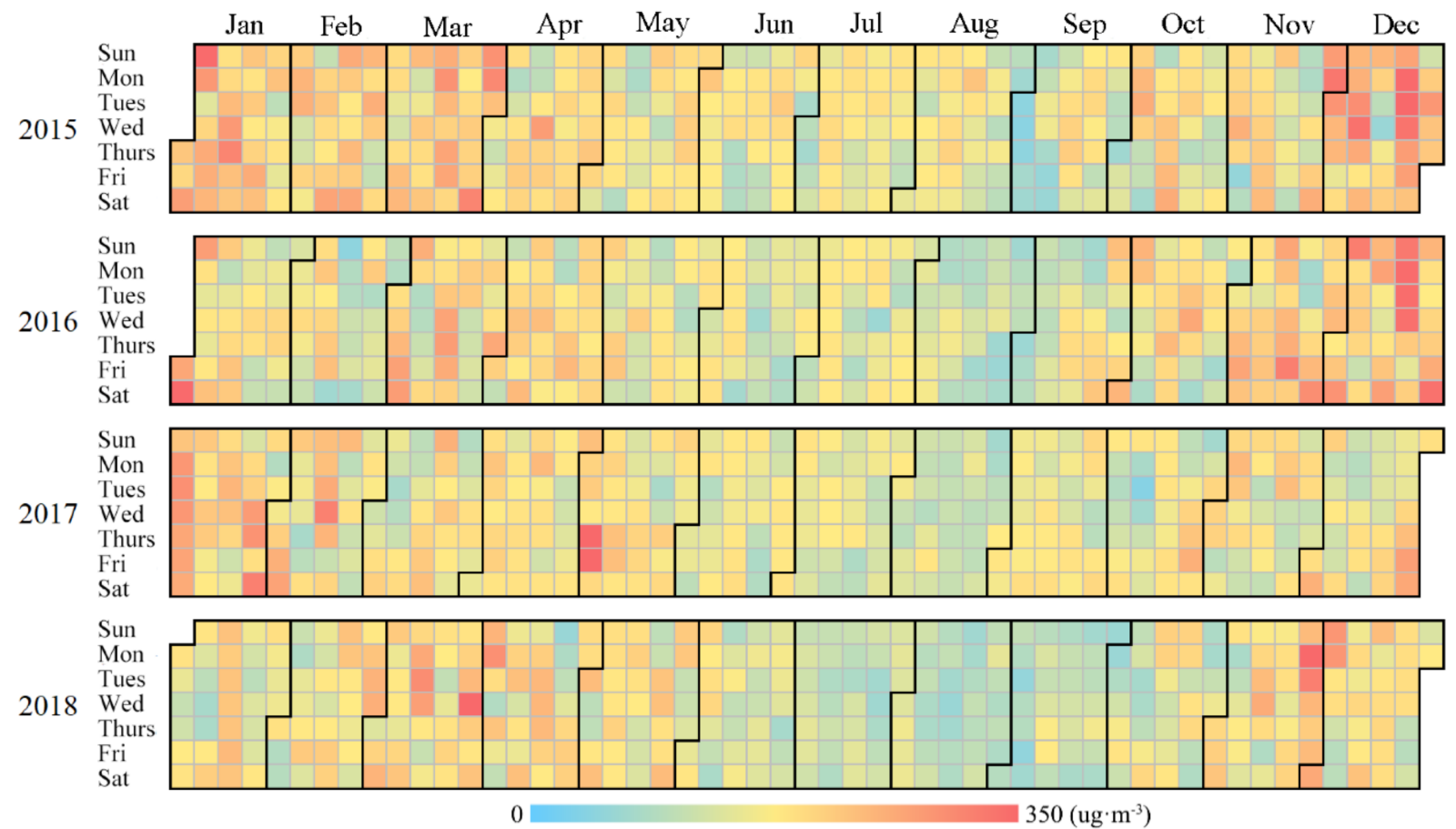

Figure 5. Thermographic calendar of daily $\mathrm{PM}_{10}$ concentration. 


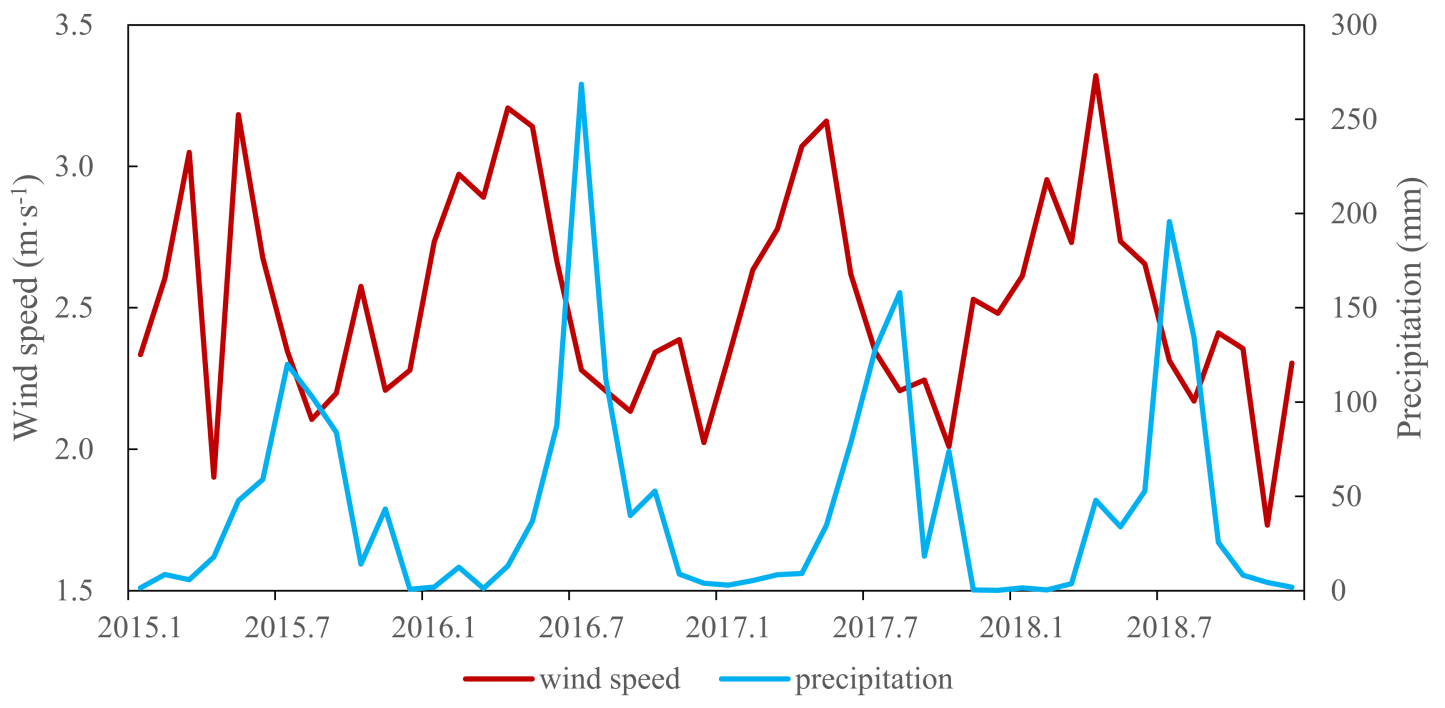

Figure 6. Variation trend of meteorological factors in the study area.

\subsubsection{Vegetation Factors}

(1) Forestland and grassland area

Table 3 show the statistics on the area and coverage rate of vegetation types in each city from 2015 to 2018. The area of forestland in the study area increased overall, and the entire forest area increased by $2190 \mathrm{~km}^{2}$. The area of DBF increased by $2568 \mathrm{~km}^{2}$, and that of shrubland decreased by $403 \mathrm{~km}^{2}$. The coniferous forest area changed very little. The grassland area showed a downwards trend, with a decrease of $2288 \mathrm{~km}$ over the past four years. In terms of stand composition, DBF was the main forest type in the study area and accounted for 93\%,94\%,95\% and 95\% of the total forest area in 2015, 2016, 2017 and 2018, respectively. Shrubland accounted for 7\%, 6\%, 4\% and 5\% in 2015, 2016, 2017 and 2018 , respectively, and coniferous forest accounted for only approximately $0.4 \%$ each year. Notably, the forestland and grassland area and coverage used in the overall scale of the city were extracted from the $500 \mathrm{~m}$ resolution land cover classification results, and only the areas where the land cover types were forestland and grassland were calculated. Forests and grasslands with small areas and unconnected plots were not considered. Therefore, the obtained results may contain some errors regarding the forest area and coverage of each city.

Table 3. Forestland and grassland coverage of each city from 2015 to 2018.

\begin{tabular}{cccccc}
\hline Time & ECF & DCF & DBF & Shrubland & Grassland \\
\hline 2015 & 107 & 29 & 29,358 & 2089 & 63,452 \\
2016 & 108 & 30 & 30,907 & 1992 & 61,000 \\
2017 & 110 & 31 & 32,621 & 1429 & 59,661 \\
2018 & 114 & 29 & 31,944 & 1686 & 61,164 \\
\hline
\end{tabular}

(Unit: $\left.\mathrm{km}^{2}\right)$.

\section{(2) LAI}

The monthly mean and spatial distribution of the LAI of forestland and grassland from 2015 to 2018 were calculated, and the results are shown in Figure 7. The monthly mean LAI of forestland and grassland in the study area changed periodically with the annual cycle and was significantly higher in summer than in winter. From November to April each year, the LAI was less than 0.5. After May, trees entered the stage of leaf spreading, and the LAI value increased rapidly to reach the highest value in August. The leaves began falling in September, and the LAI value dropped rapidly and then returned to a lower level in October. The variation in LAI was closely related to vegetation growth. Because the 
study area contains little evergreen vegetation, the LAI increased rapidly with the growth of leaves in spring and summer, and the LAI declined rapidly when the leaves began to fall after autumn and reached the lowest level in winter. Among the monthly mean LAI values, the highest value of 2.30 occurred in August, and the lowest value of 0.17 occurred in January. The highest LAI value appeared in August 2016 and reached 2.43, and the lowest value appeared in November 2015 and reached 0.13 .
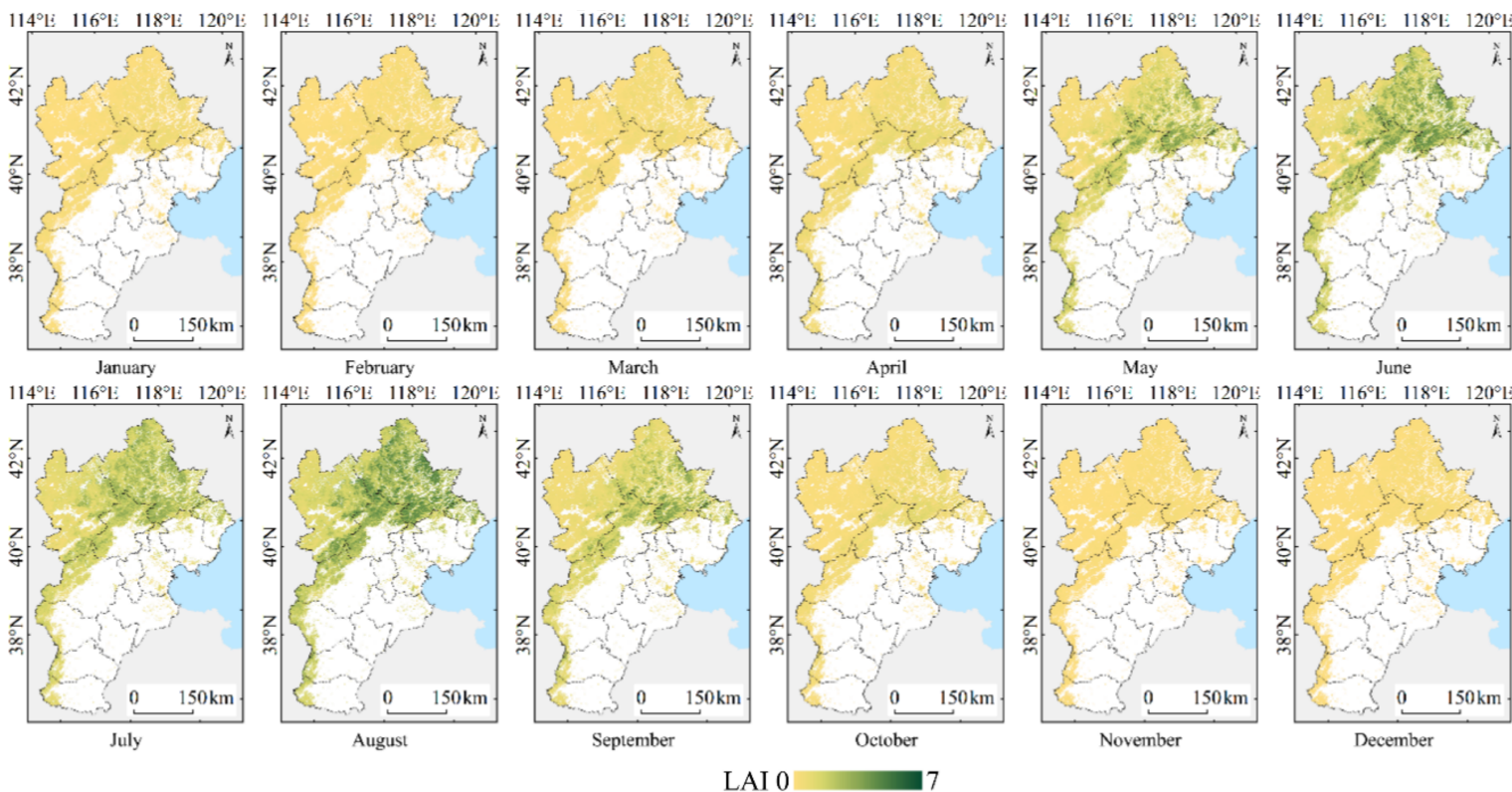

Figure 7. Spatial distribution of monthly mean values of LAI from 2015 to 2018.

The monthly mean LAI values of various vegetation types in the study area were calculated, and the results are shown in Figure 8. The LAI of ECF and DCF was slightly higher than those of the DBF and shrubland in the months with a low LAI. The LAI of DBF and shrubland were significantly higher than those of ECF and DCF in the months with a high LAI. Because the DBF and shrubland accounted for a large proportion of all vegetation types, the temporal variation pattern of the LAI was basically consistent with the LAI of the entire study area. The monthly LAI of grassland was lower than that of forestland. The annual average LAI values of the ECF, DCF, DBF, shrubland and grassland vegetation types were $1.01,0.98,1.34,1.27$ and 0.69 , respectively.

4

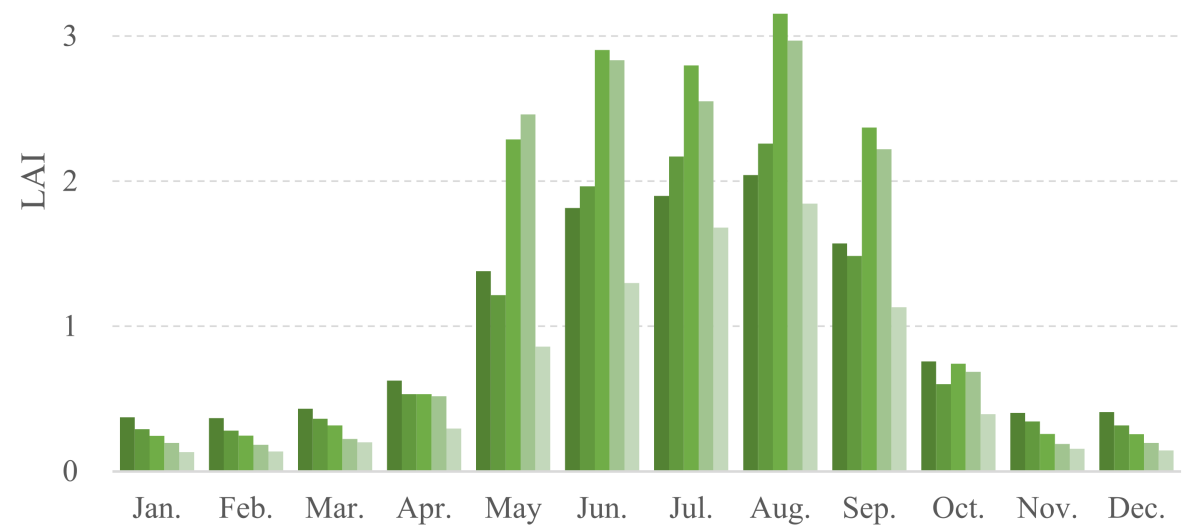

Figure 8. Monthly mean value of LAI of each forest stand from 2015 to 2018. 


\subsection{Analysis of the Total Scale of Cities}

3.3.1. Reduction Effect of Vegetation Factors on $\mathrm{PM}_{10}$

Using the calculation methods above, we quantified the emission reduction effect of vegetation on the whole city and built-up area. The total amount of $\mathrm{PM}_{10}$ reduced by forestland and grassland in the BTH area was 505,200 t, 465,500 t, 477,200 $t$ and 396,500 $t$ in 2015, 2016, 2017 and 2018, respectively, and the reduction per unit area was $5.32 \mathrm{~g} \cdot \mathrm{m}^{-2}$, $4.95 \mathrm{~g} \cdot \mathrm{m}^{-2}, 5.09 \mathrm{~g} \cdot \mathrm{m}^{-2}$ and $4.19 \mathrm{~g} \cdot \mathrm{m}^{-2}$, respectively. The concentration of $\mathrm{PM}_{10}$ was reduced by $0.454 \mu \mathrm{g} \cdot \mathrm{m}^{-3}, 0.417 \mu \mathrm{g} \cdot \mathrm{m}^{-3}, 0.429 \mu \mathrm{g} \cdot \mathrm{m}^{-3}$ and $0.356 \mu \mathrm{g} \cdot \mathrm{m}^{-3}$ in 2015,2016 , 2017 and 2018 in forestland and grassland in the BTH area, respectively, which reduced the concentration of $\mathrm{PM}_{10}$ by $0.366 \%, 0.374 \% 0.397 \%$ and $0.355 \%$, respectively.

Figure 9 show the statistics of the monthly $\mathrm{PM}_{10}$ reduction and unit area reduction on the overall scale of the city from 2015 to 2018. The annual reduction in each month primarily occurred from May to September, and the reduction in these five months accounted for greater than $85 \%$ of the reduction for the entire year. The monthly reductions were $82,000 \mathrm{t}, 80,000 \mathrm{t}, 94,000 \mathrm{t}, 89,000 \mathrm{t}$ and 55,000 $\mathrm{t}$ in May, June, July, August and September, respectively. The monthly decline was highest in August 2015 and reached 125,000 tons, and the lowest decline was 0.3 tons in February 2016. The reduction per unit area from May to September was significantly higher than that in the other months, with values of $0.87 \mathrm{~g} \cdot \mathrm{m}^{-2}, 0.85 \mathrm{~g} \cdot \mathrm{m}^{-2}, 1.00 \mathrm{~g} \cdot \mathrm{m}^{-2}, 0.95 \mathrm{~g} \cdot \mathrm{m}^{-2}$ and $0.58 \mathrm{~g} \cdot \mathrm{m}^{-2}$ in May, June, July, August and September, respectively. The differences in monthly reduction were primarily due to the change in LAI. The BTH area has four distinct seasons. The period from May to September corresponds to the growth season of trees and grass. The effective dust-retaining area increased during this time, and the reduction in PM was significantly enhanced.

150,000

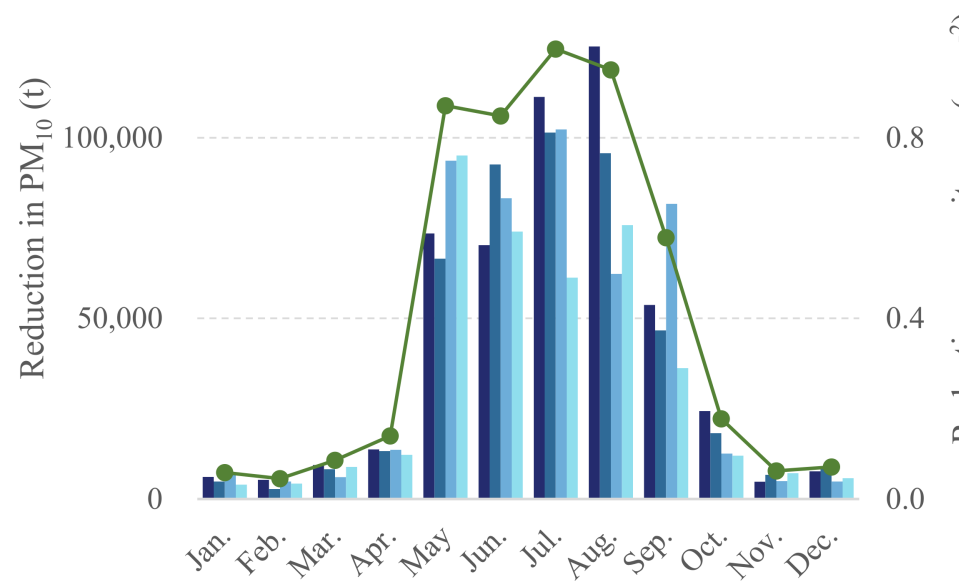

1.2

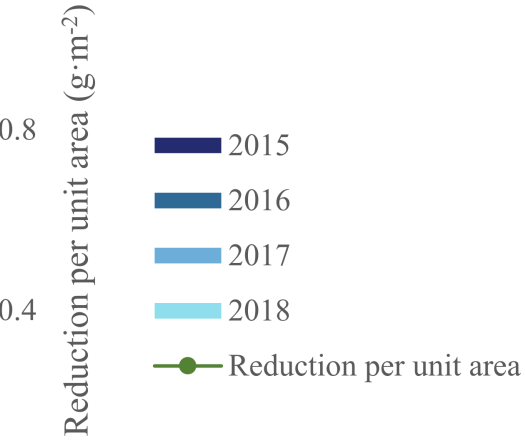

Figure 9. $\mathrm{PM}_{10}$ removal of each month at an overall scale from 2015 to 2018.

The total amount of $\mathrm{PM}_{10}$ reduction and the reduction in vegetation types per unit area in the whole city from 2015 to 2018 were counted, and the results are shown in Figure 10. Among all vegetation types, DBF was the most important stand type in the BTH area, which was the main source of $\mathrm{PM}_{10}$ reduction and accounted for $78.6 \%, 78.5 \%, 80.3 \%$ and $76.8 \%$ of the total reduction in 2015, 2016, 2017 and 2018, respectively. ECF and DCF accounted for approximately $0.2 \%$ and $0.1 \%$ of the total reduction, respectively, annually. The shrubland area was smaller than the DBF and grassland area, and it contributed approximately $4.1 \%$ of the total decrease each year. Although the area of grassland was much larger than that of forestland, the reduction rate of PM was approximately $17.1 \%$ due to the low efficiency in grassland. The unit area reduction of DBF and shrubland was relatively high and reached $11.65 \mathrm{~g} \cdot \mathrm{m}^{-2}$ and $10.61 \mathrm{~g} \cdot \mathrm{m}^{-2}$, respectively; the unit area reduction was $8.02 \mathrm{~g} \cdot \mathrm{m}^{-2}$ and $7.69 \mathrm{~g} \cdot \mathrm{m}^{-2}$ for ECF and DCF, respectively, and only $1.28 \mathrm{~g} \cdot \mathrm{m}^{-2}$ for grassland. These results showed that DBF contributed more to the reduction in $\mathrm{PM}_{10}$ in the $\mathrm{BTH}$ region. 


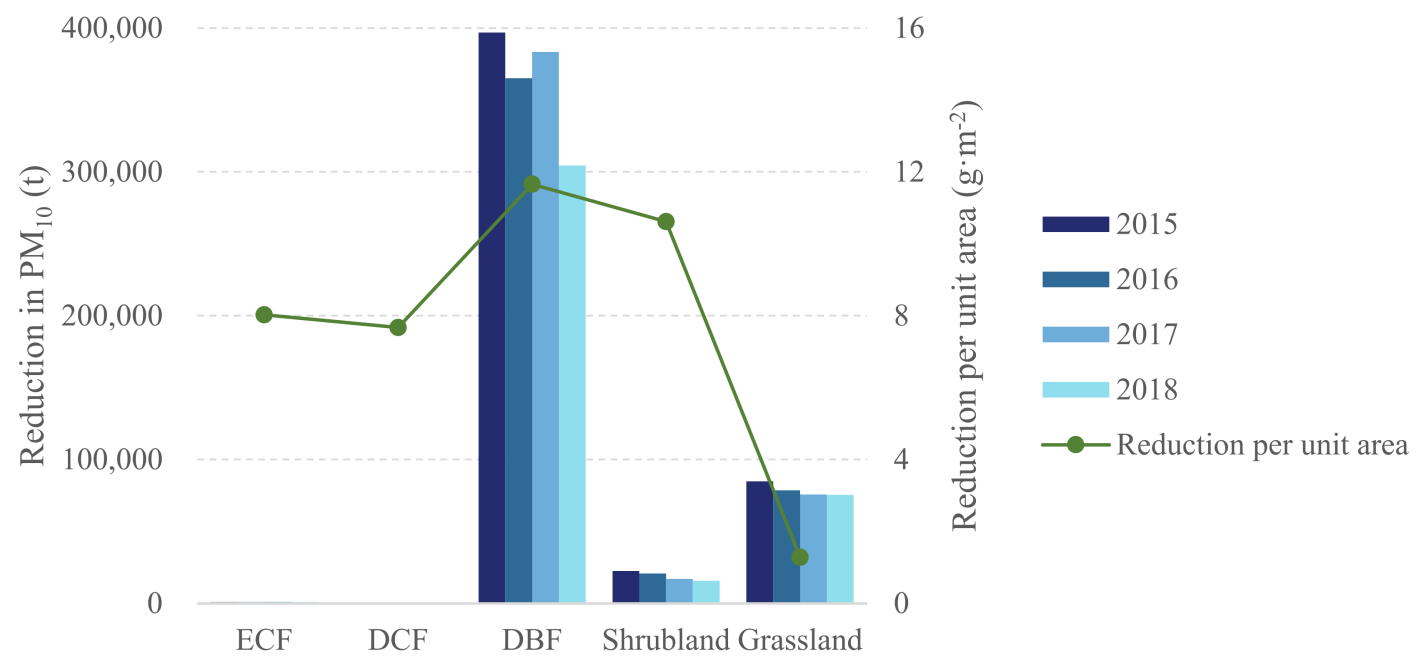

Figure 10. $\mathrm{PM}_{10}$ removal of each vegetation type at the overall scale from 2015 to 2018.

\subsubsection{Reduction Effect of Vegetation Factors on $\mathrm{PM}_{2.5}$}

The total amounts of $\mathrm{PM}_{2.5}$ reduction in forestland and grassland in the BTH area in 2015, 2016, 2017 and 2018 were 19,400 t, 19,200 t, 16,400 $t$ and 12,700 t, respectively. The reductions per unit area were $0.20 \mathrm{~g} \cdot \mathrm{m}^{-2}, 0.20 \mathrm{~g} \cdot \mathrm{m}^{-2}, 0.17 \mathrm{~g} \cdot \mathrm{m}^{-2}$ and $0.13 \mathrm{~g} \cdot \mathrm{m}^{-2}$, respectively. The concentrations of $\mathrm{PM}_{2.5}$ in forestland and grassland in the $\mathrm{BTH}$ area were reduced by $0.017 \mu \mathrm{g} \cdot \mathrm{m}^{-3}, 0.017 \mu \mathrm{g} \cdot \mathrm{m}^{-3}, 0.015 \mu \mathrm{g} \cdot \mathrm{m}^{-3}$ and $0.011 \mu \mathrm{g} \cdot \mathrm{m}^{-3}$ in 2015 , 2016, 2017 and 2018, respectively, and the concentrations of $\mathrm{PM}_{2.5}$ were reduced by $0.025 \%$, $0.027 \%, 0.025 \%$ and $0.023 \%$, respectively. Similar to the settlement results of the $\mathrm{PM}_{10}$ reduction effect, the significant reduction in PM concentration over the four years resulted in a decrease in the total reduction amount and the reduction amount per unit area in the study area. Compared with $\mathrm{PM}_{10}$, the reduction in $\mathrm{PM}_{2.5}$ by vegetation was relatively low, which indicated that the reduction effect of vegetation on particles with larger aerodynamic equivalent diameters was more obvious. Because $\mathrm{PM}_{2.5}$ particles are relatively small, they do not readily settle via gravity, and the dry settlement is significantly lower than that of $\mathrm{PM}_{10}[19,47]$. Measurements of aerosol fluxes using eddy methods in different regions and towns showed limited deposition of ultrafine particles but an increased frequency of deposition of fine and coarse particles, which was consistent with the research results of other scholars [48,49].

The total amount of $\mathrm{PM}_{2.5}$ reduction and the amount of reduction per unit area from 2015 to 2018 were calculated, and the results are shown in Figure 11. The annual reduction was primarily concentrated from May to September. The reduction in these five months accounted for greater than $80 \%$ of the reduction for the entire year and reached $91.9 \%$ in 2017. The average monthly reductions in May, June, July, August and September were $2171 \mathrm{t}, 3642 \mathrm{t}, 3689 \mathrm{t}, 3060 \mathrm{t}$ and $2188 \mathrm{t}$, respectively. The reduction per unit area was significantly higher in May, June, July, August and September $\left(0.023 \mathrm{~g} \cdot \mathrm{m}^{-2}, 0.039 \mathrm{~g} \cdot \mathrm{m}^{-2}\right.$, $0.039 \mathrm{~g} \cdot \mathrm{m}^{-2}, 0.032 \mathrm{~g} \cdot \mathrm{m}^{-2}$ and $0.023 \mathrm{~g} \cdot \mathrm{m}^{-2}$, respectively) than in the other months. The change in leaf area was the main reason for the differences in the reduction value each month. The decline was the highest in June 2016 and reached $4668 \mathrm{t}$, and it was negative in January 2018 and reached -18 t. From November 2017 to mid-March 2018, very little precipitation occurred in the BTH area. According to the observation standard, an effective precipitation day was when the daily precipitation of a meteorological observation was greater than $0.1 \mathrm{~mm}$. Using Beijing as an example, no effective precipitation occurred for 145 days from 23 October 2017 to 16 March 2018, the longest record ever. A long-term lack of effective precipitation led to a gradual increase in PM accumulation on leaves. When the wind speed was high, the resuspension amount exceeded the dry sedimentation amount, which led to a negative value. 
Statistics of the total amount of $\mathrm{PM}_{2.5}$ reduction and the reduction in vegetation types per unit area in the whole city were calculated from 2015 to 2018, and the results are shown in Figure 12. Among all vegetation types, the decline in DBF in 2015, 2016, 2017 and 2018 accounted for $73.2 \%, 73.9 \%, 75.9 \%$ and $72.8 \%$ of the total decline, respectively. ECF and DCF accounted for approximately $0.2 \%$ and $0.1 \%$ of the total annual reduction, respectively. The shrubland area was smaller than the DBF and grassland areas, and it accounted for approximately $3.4 \%$ of the total annual decrease. Although the area of grassland was much larger than that of forestland, the reduction rate of PM was approximately $22.4 \%$ due to low efficiency. The reduction per unit area of DBF forest was relatively high and reached $0.40 \mathrm{~g} \cdot \mathrm{m}^{-2}$, and the reductions in shrubland, ECF and DCF were $0.32 \mathrm{~g} \cdot \mathrm{m}^{-2}, 0.30 \mathrm{~g} \cdot \mathrm{m}^{-2}$ and $0.30 \mathrm{~g} \cdot \mathrm{m}^{-2}$, respectively. The reduction per unit area of grassland was only $0.06 \mathrm{~g} \cdot \mathrm{m}^{-2}$. In contrast to $\mathrm{PM}_{10}, \mathrm{DBF}$ remained the most important vegetation type for $\mathrm{PM}_{2.5}$ reduction, but the relative contribution of DBF to total $\mathrm{PM}_{2.5}$ reduction was lower than its contribution to $\mathrm{PM}_{10}$ reduction, and grassland accounted for a larger proportion of $\mathrm{PM}_{2.5}$ reduction.

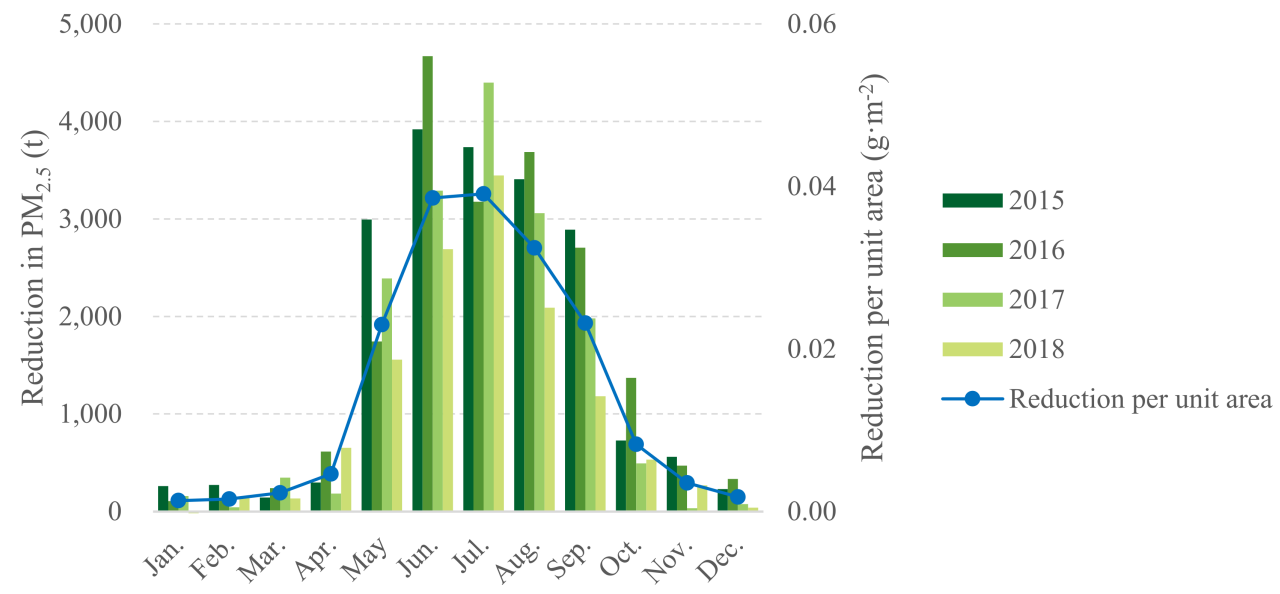

Figure 11. $\mathrm{PM}_{2.5}$ removal of each month at the overall scale from 2015 to 2018.

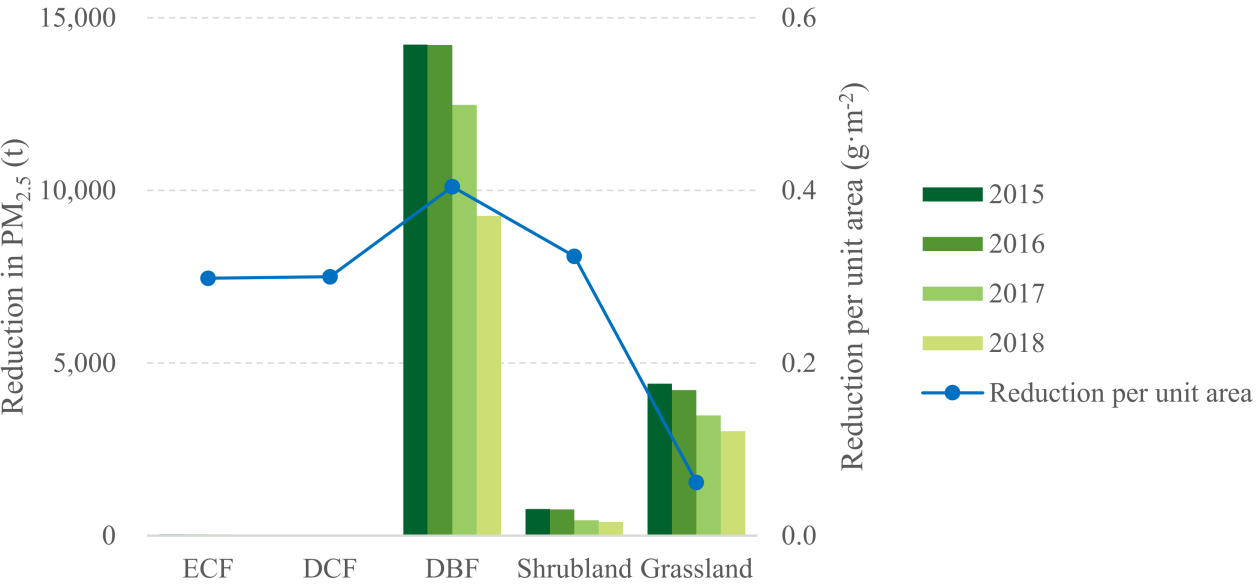

Figure 12. $\mathrm{PM}_{2.5}$ removal of each vegetation type at the overall scale from 2015 to 2018.

\subsection{Analysis on the Scale of the Built-Up Area}

3.4.1. Reduction Effect of Vegetation Factors on $\mathrm{PM}_{10}$

The calculation results showed the reduction effect of all forestland and grassland on PM in the whole region, and the built-up area scale emphasized the reduction effect of urban green space on PM in the built-up area. Urban green space generally refers to urban land with natural and artificial vegetation as the main forms, including green park space, green production space, protected green space, subsidiary green space and other green spaces. The main types of land use are forestland, shrubland and grassland. Built-up areas 
are the main places for human activities, and the air quality of built-up areas has a more direct impact on human life. Urban green spaces are primarily distributed in built-up areas. Because the concentration of PM in built-up areas is generally higher than that in other areas, urban green space reduces PM more directly.

The calculation results showed that the total amount of $\mathrm{PM}_{10}$ in the urban green space in the BTH area in 2015, 2016, 2017 and 2018 was 8616 t, 8319 t, $8648 t$ and 7227 t, respectively, and the reduction amount per unit area was $3.03 \mathrm{~g} \cdot \mathrm{m}^{-2}, 2.91 \mathrm{~g} \cdot \mathrm{m}^{-2}, 3.00 \mathrm{~g} \cdot \mathrm{m}^{-2}$ and $2.45 \mathrm{~g} \cdot \mathrm{m}^{-2}$, respectively. The $\mathrm{PM}_{10}$ concentration was reduced by $0.101 \mu \mathrm{g} \cdot \mathrm{m}^{-3}$, $0.096 \mu \mathrm{g} \cdot \mathrm{m}^{-3}, 0.099 \mu \mathrm{g} \cdot \mathrm{m}^{-3}$ and $0.082 \mu \mathrm{g} \cdot \mathrm{m}^{-3}$ per hour and was reduced by $0.079 \%$, $0.082 \%, 0.088 \%$ and $0.080 \%$, respectively. Although the area of urban green space increased slightly in the past four years due to a series of measures, such as the promotion of clean energy, the improvement of motor vehicle oil quality and the renovation and relocation of urban factories, the amount of urban green space that is available to reduce PM and the amount of reduction per unit area decreased slightly.

Figures 13-15 show the statistics of the $\mathrm{PM}_{10}$ reduction amount and reduction amount per unit area in cities, months and vegetation types on the overall scale of cities from 2015 to 2018. The reduction in Beijing was far greater than that in the other cities and reached $4509 \mathrm{t}, 4784 \mathrm{t}, 4856 \mathrm{t}$ and $3862 \mathrm{t}$ in 2015, 2016, 2017 and 2018, respectively. The average annual reduction in built-up areas in Tangshan and Tianjin exceeded $500 \mathrm{t}$, and the reduction in Cangzhou, Langfang and Hengshui was less than $100 \mathrm{t}$. The regional difference was primarily caused by the difference in urban green space areas. The green space area in Beijing is approximately $2900 \mathrm{~km}^{2}$, which is much larger than that of the other cities. Among the cities, the maximum reduction per unit area was $7.37 \mathrm{~g} \cdot \mathrm{m}^{-2}$ in Chengde, followed by $4.52 \mathrm{~g} \cdot \mathrm{m}^{-2}$ and $3.37 \mathrm{~g} \cdot \mathrm{m}^{-2}$ in Handan and Beijing, respectively. Similar to the calculation results of the overall scale of the city, the reduction in each month was primarily concentrated from May to September and accounted for $84.6 \%$ of the reductions for the entire year. The reductions in May, June, July, August and September were $1559 \mathrm{t}, 1361 \mathrm{t}$, $1497 \mathrm{t}, 14,829 \mathrm{t}$ and $1044 \mathrm{t}$, respectively. August 2015 had the highest value of $1855 \mathrm{t}$, and February 2016 had the lowest value. The maximum reduction per unit area in each month was $0.54 \mathrm{~g} \cdot \mathrm{m}^{-2}$ in May, and the minimum was $0.03 \mathrm{~g} \cdot \mathrm{m}^{-2}$ in February. Among the green space types, forestland, shrubland and grassland contributed $53.2 \%, 2.2 \%$ and $44.6 \%$ of the total reduction, respectively, and the reduction per unit area was $11.16 \mathrm{~g} \cdot \mathrm{m}^{-2}, 10.86 \mathrm{~g} \cdot \mathrm{m}^{-2}$ and $1.48 \mathrm{~g} \cdot \mathrm{m}^{-2}$, respectively. Compared with the calculation results at the whole-city scale, grassland contributed more to the total reduction because grassland was the main type of urban green space, and its proportion of the green space area was much larger than that of forestland.

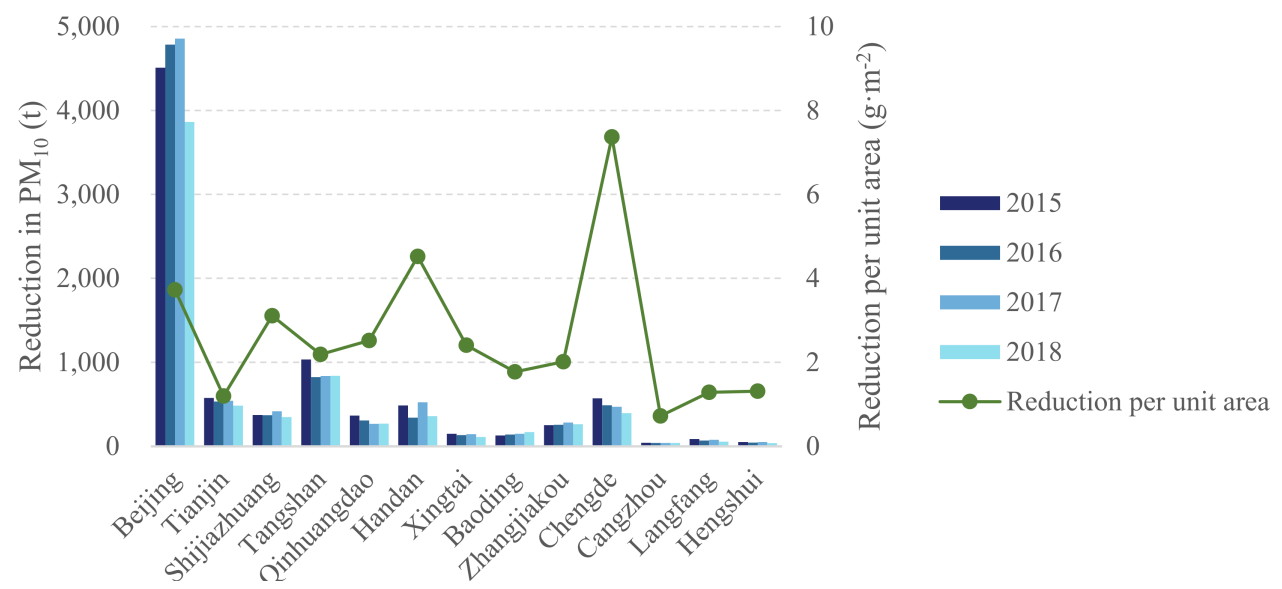

Figure 13. $\mathrm{PM}_{10}$ removal of each city at the built-up area scale from 2015 to 2018. 


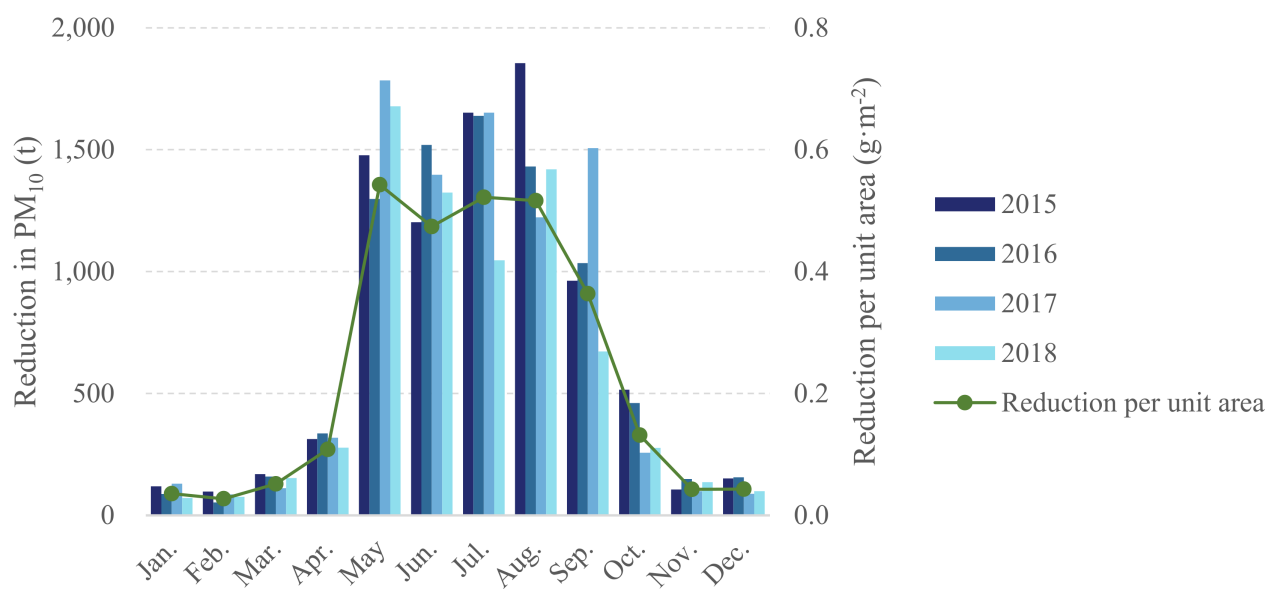

Figure 14. $\mathrm{PM}_{10}$ removal in each month at the built-up area scale from 2015 to 2018.

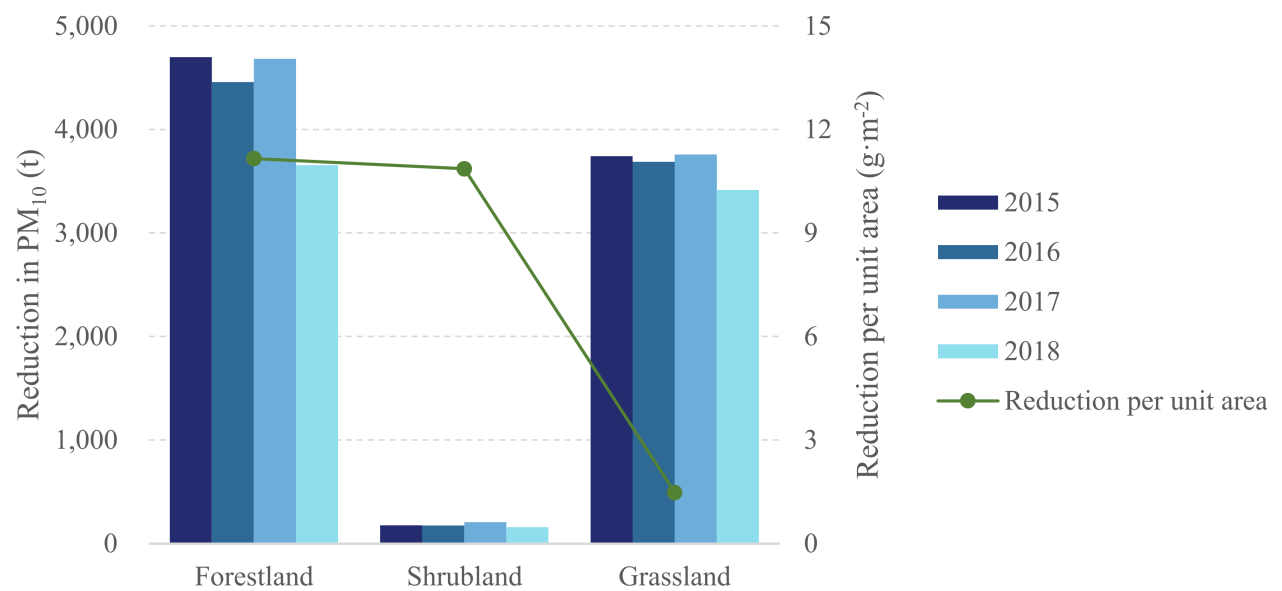

Figure 15. $\mathrm{PM}_{10}$ removal of each green space type at the built-up area scale from 2015 to 2018 .

\subsubsection{Reduction Effect of Vegetation Factors on $\mathrm{PM}_{2.5}$}

The total amounts of $\mathrm{PM}_{2.5}$ in the urban green space in the BTH area were $360 \mathrm{t}, 388 \mathrm{t}$, $277 \mathrm{t}$ and $237 \mathrm{t}$ in 2015, 2016, 2017 and 2018, respectively, and the reductions per unit area were $0.13 \mathrm{~g} \cdot \mathrm{m}^{-2}, 0.14 \mathrm{~g} \cdot \mathrm{m}^{-2}, 0.10 \mathrm{~g} \cdot \mathrm{m}^{-2}$ and $0.08 \mathrm{~g} \cdot \mathrm{m}^{-2}$, respectively. The concentrations of $\mathrm{PM}_{2.5}$ were reduced by $0.004 \mu \mathrm{g} \cdot \mathrm{m}^{-3}, 0.004 \mu \mathrm{g} \cdot \mathrm{m}^{-3}, 0.003 \mu \mathrm{g} \cdot \mathrm{m}^{-3}$ and $0.003 \mu \mathrm{g} \cdot \mathrm{m}^{-3}$ per hour, which were reductions of $0.006 \%, 0.006 \%, 0.005 \%$ and $0.005 \%$, respectively. The reduction amount, concentration reduction value and concentration improvement rate of $\mathrm{PM}_{10}$ by vegetation were significantly higher than those of $\mathrm{PM}_{2.5}$, which demonstrated that the reduction effect of vegetation on particles with larger aerodynamic equivalent diameters was more obvious. However, because $\mathrm{PM}_{2.5}$ had a stronger correlation with human production and living activities, the reduction effect of vegetation on $\mathrm{PM}_{2.5}$ should not be ignored.

Statistics were applied to the total amount of $\mathrm{PM}_{2.5}$ reduction and the amount of reduction per unit area of each city, month and vegetation type on the overall scale of cities from 2015 to 2018, and the results are shown in Figures 16-18. Among the cities, the reduction in Beijing was larger than that in the other cities and reached $193 \mathrm{t}, 211 \mathrm{t}$, $142 \mathrm{t}$ and $128 \mathrm{t}$ in 2015, 2016, 2017 and 2018, respectively, and the reductions in Cangzhou, Langfang and Hengshui were relatively low. Among the cities, the maximum reduction per unit area was $0.30 \mathrm{~g} \cdot \mathrm{m}^{-2}$ in Chengde, followed by $0.15 \mathrm{~g} \cdot \mathrm{m}^{-2}$ and $0.14 \mathrm{~g} \cdot \mathrm{m}^{-2}$ in Handan and Beijing, respectively. The monthly reduction from May to September accounted for $86.9 \%$ of the reduction for the entire year, and the reductions in May, June, July, August and September were $38 \mathrm{t}, 72 \mathrm{t}, 69 \mathrm{t}, 54 \mathrm{t}$ and $40 \mathrm{t}$, respectively. The highest value of $105 \mathrm{t}$ was observed in June 2016, and the highest reduction per unit area in June was $0.03 \mathrm{~g} \cdot \mathrm{m}^{-2}$. 
Among the green space types, forestland, shrubland and grassland contributed $44.8 \%$, $1.7 \%$ and $53.5 \%$ of the total reduction, respectively, and the reduction per unit area was $0.36 \mathrm{~g} \cdot \mathrm{m}^{-2}, 0.33 \mathrm{~g} \cdot \mathrm{m}^{-2}$ and $0.07 \mathrm{~g} \cdot \mathrm{m}^{-2}$, respectively. Grassland was the main green space type for reducing $\mathrm{PM}_{2.5}$ in cities.

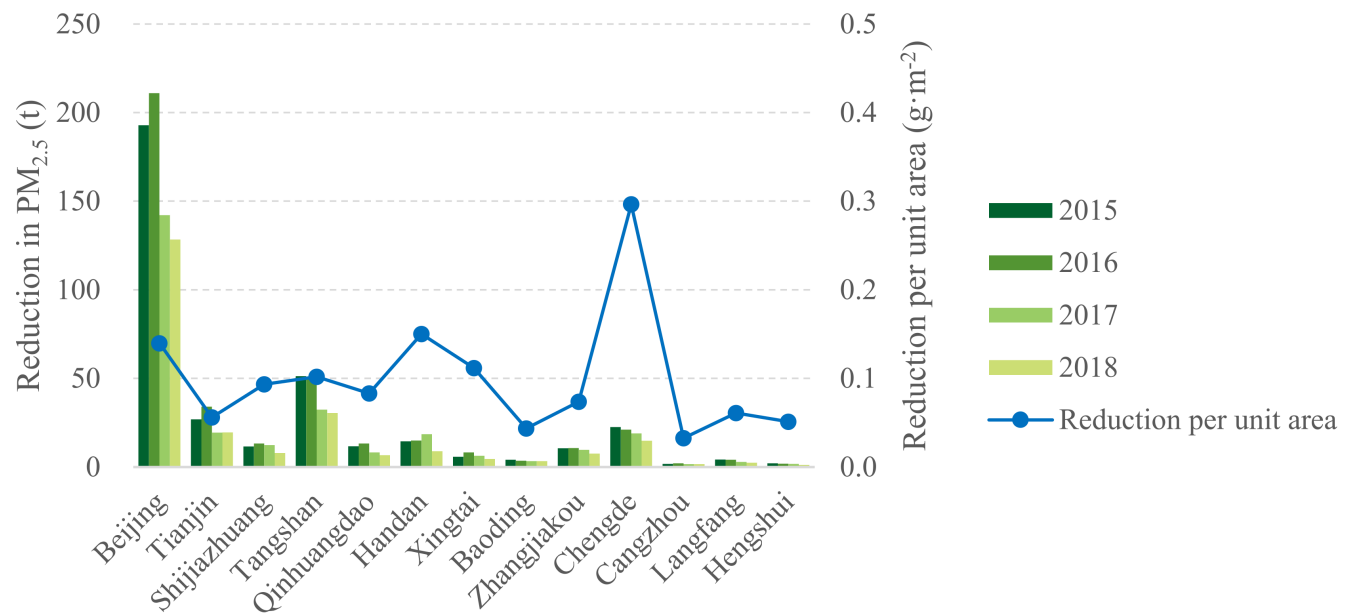

Figure 16. $\mathrm{PM}_{2.5}$ removal of each city at the built-up area scale from 2015 to 2018 .

120

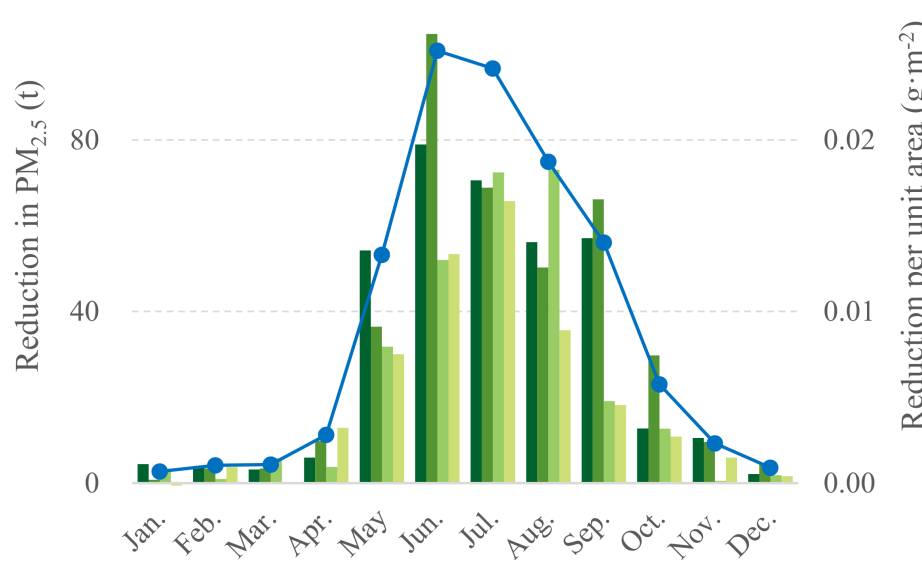

0.03

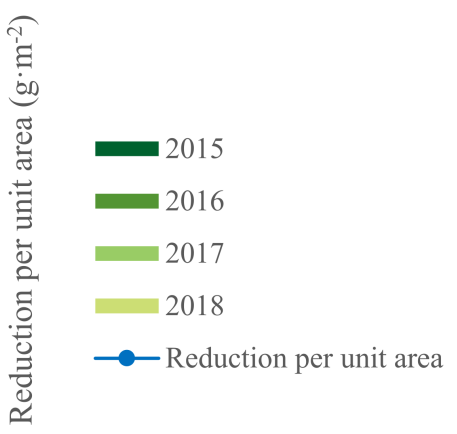

Figure 17. $\mathrm{PM}_{2.5}$ removal each month at the built-up area scale from 2015 to 2018 .

250

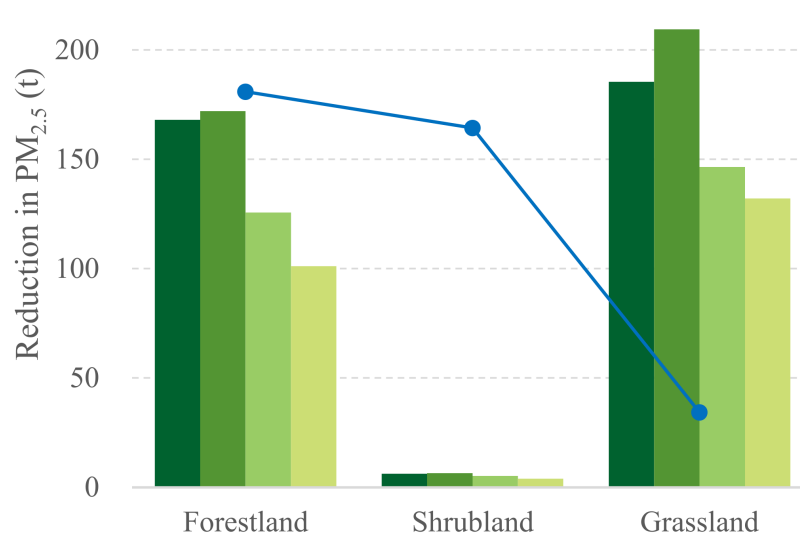

0.5

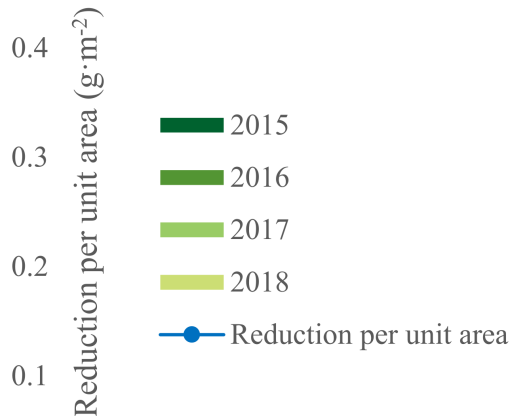

0.0

Figure 18. $\mathrm{PM}_{2.5}$ removal of each green space type at the built-up area scale from 2015 to 2018 . 


\section{Discussion}

\subsection{Comparisons with Other Studies}

Research on $\mathrm{PM}_{10}$ reduction in foreign countries started earlier. Nowak et al. [19] estimated the reduction in PM in 55 cities in the United States and found that the annual reduction in each city ranged from $22 \mathrm{t}$ to $11,000 \mathrm{t}$, and the reduction per unit area ranged from $6.2 \mathrm{~g} \cdot \mathrm{m}^{-2}$ to $23.1 \mathrm{~g} \cdot \mathrm{m}^{-2}$, with a median of $10.8 \mathrm{~g} \cdot \mathrm{m}^{-2}$. The experimental results of Escobedo et al. [22,41] in the Santiago metropolitan area, Chile, showed that the annual removal of $\mathrm{PM}_{10}$ by forest was approximately $1754 \mathrm{t}$, and the reduction of $\mathrm{PM}_{10}$ per unit area by forestland, shrubland and grassland was $7.4-8.0 \mathrm{~g} \cdot \mathrm{m}^{-2}, 5.7-8.5 \mathrm{~g} \cdot \mathrm{m}^{-2}$ and $1.73 \mathrm{~g} \cdot \mathrm{m}^{-2}$, respectively. McDonald et al. [43] demonstrated that the vegetation in the West Midlands of England removed up to $110 \mathrm{t}$ of $\mathrm{PM}_{10}$ each year. Tallis et al. [11] demonstrated that the annual reduction in $\mathrm{PM}_{10}$ by forests in Greater London was approximately $852 \mathrm{t}-2121 \mathrm{t}$. Scott et al. [50] calculated that the annual reduction in $\mathrm{PM}_{10}$ by forests was $679 \mathrm{t}$. More recent scholars have turned their attention to the study of $\mathrm{PM}_{2.5}$ reduction. Although the reduction in $\mathrm{PM}_{2.5}$ by vegetation is much lower than that of $\mathrm{PM}_{10}$, it is more closely related to human health. Nowak et al. [47] estimated the annual reduction in $\mathrm{PM}_{2.5}$ in 10 cities in the United States and found that the reduction amount varied from $4.7 \mathrm{t}$ in Syracuse to $64.5 \mathrm{t}$ in Atlanta, with the reduction amount per unit area ranging from $0.13 \mathrm{~g} \cdot \mathrm{m}^{-2}$ to $0.36 \mathrm{~g} \cdot \mathrm{m}^{-2}$ and the concentration reduction value per hour ranging from $0.006 \mu \mathrm{g} \cdot \mathrm{m}^{-3}$ to $0.033 \mu \mathrm{g} \cdot \mathrm{m}^{-3}$. Nowak et al. [18] showed that trees in 86 cities in Canada removed $665 \mathrm{t}$ of $\mathrm{PM}_{2.5}$ in 2010 , with a reduction of $0.15 \mathrm{~g} \cdot \mathrm{m}^{-2}$ per unit area, a change in concentration of approximately $0.009 \mu \mathrm{g} \cdot \mathrm{m}^{-3}$ and a concentration improvement rate of approximately $0.145 \%$

Research by Chinese scholars on the reduction of PM by vegetation is limited. Yang et al. [35] showed that the trees in the eight central urban areas of Beijing removed a total of $1261.4 \mathrm{t}$ of pollutants in 2002, of which the total reduction in $\mathrm{PM}_{10}$ was $772 \mathrm{t}$, and the reduction per unit area was approximately $16.8 \mathrm{~g} \cdot \mathrm{m}^{-2}$ per year. Chang Yamin [51] showed that the total reduction in $\mathrm{PM}_{2.5}$ by afforestation in the plains area of Beijing in 2012 was approximately $26.66 \mathrm{t}$, and the removal amount per unit leaf area was approximately $0.27 \mathrm{~g} \cdot \mathrm{m}^{-2}$. The experimental results above are similar to some of the results related to forestland in the current experiment. According to Xiao Yu et al. [17], the total amount of $\mathrm{PM}_{2.5}$ was reduced by $1861 \mathrm{t}, 2987 \mathrm{t}$ and $3852 \mathrm{t}$ in 2000, 2005 and 2010, respectively; the reduction amount per unit area was $2.27 \mathrm{~g} \cdot \mathrm{m}^{-2}, 2.46 \mathrm{~g} \cdot \mathrm{m}^{-2}$ and $3.34 \mathrm{~g} \cdot \mathrm{m}^{-2}$, respectively; and the improvement rate of $\mathrm{PM}_{2.5}$ concentration was $0.07 \%, 0.12 \%$ and $0.19 \%$, respectively. Chen Long et al. [52] showed that the total amount of $\mathrm{PM}_{2.5}$ reduction by afforestation in the plains area of Beijing in 2012 was $451 \mathrm{t}$, and the reduction per unit area was approximately $2.66 \mathrm{~g} \cdot \mathrm{m}^{-2}$, which reduced the concentration of $\mathrm{PM}_{2.5}$ by $0.57 \mu \mathrm{g} \cdot \mathrm{m}^{-3}$ on average. Cao Hongliang et al. [16] showed that the total amount of $\mathrm{PM}_{2.5}$ in the Shanghai urban forest was approximately $442.4 \mathrm{t}$ in 2013 , which reduced the concentration of $\mathrm{PM}_{2.5}$ by $0.44 \mu \mathrm{g} \cdot \mathrm{m}^{-3}$ on average, and the improvement rate of the $\mathrm{PM}_{2.5}$ concentration was $0.07 \%$. The experimental results above are slightly higher than our experimental results, primarily because of the different calculation methods. The daily time step was used in the above studies, and only the daily dry settlement on nonprecipitation days was considered when calculating the resuspension of $\mathrm{PM}_{2.5}$. To determine the resuspension of $\mathrm{PM}_{2.5}$ in the present experiment, the sum of the accumulated PM on the leaves after the last effective precipitation and the current dry settlement was calculated, which led to some differences in the results. Because the amount of fine particles absorbed by vegetation is low, most of these particles return to the atmosphere due to resuspension. Therefore, leaf accumulation should be considered when calculating the resuspension amount to increase the accuracy of the results.

\subsection{Error Analysis}

This manuscript estimated the reduction effect of vegetation on $\mathrm{PM}_{2.5}$ and $\mathrm{PM}_{10}$ in the BTH area at the scales of the whole city and built-up area. The estimation process may involve some errors. The error sources may include the following factors. (1) The 
dry settlement rate in the experiment was calculated based on literature reports, and the same calculation method was adopted for different tree species. The dry sedimentation rates of different tree species may be different, and the planting structure of tree species in the literature and the BTH local tree species may be different, resulting in potential errors. (2) The related literature includes many experiments on the effect of forestland on PM reduction, but few studies have focused on grassland. The current paper set the dry settlement rate of grassland to $1 / 3$ of the rate of forestland with reference to the experience of foreign scholars, and different grassland types were not distinguished. (3) The resuspension rate was not considered in the calculation of $\mathrm{PM}_{10}$ reduction, and the amount of dust retention by leaves may reach saturation without effective precipitation for a long time, which was not considered in the experiment. (4) The boundary layer height should be considered when calculating the particle stock and concentration improvement rate in the entire region. The boundary layer height fluctuates in different spatial positions and different times, and only different seasons were distinguished in the experiment. (5) When calculating the whole scale of the city, the forestland and grassland area data were extracted from the results of large-scale land use classification, and forests and grasslands with small areas and unconnected plots were not considered. This approach may also have an impact on the calculation results. (6) The spatial distribution data on PM concentration used in the experiment were based on the measured data of air quality monitoring stations and obtained using the kriging method of spatial interpolation. Due to the limited number of stations and uneven spatial distribution, some errors may occur between the interpolation results and the actual data at some spatial positions far away from the stations.

Despite these influences, this experiment made some improvements to the traditional methods. (1) It divided the large area into several small areas, divided the forestland into different types according to different stands, extracted the LAI values of various vegetation types in different places, calculated the amount of PM reduction and summed the results to obtain the total amount of reduction in the study area. (2) The present experiment quantified the reduction of PM in forestland and grassland on the scale of the whole city and the reduction of urban green space on the scale of the built-up area and compared their similarities and differences. The experimental results are highly relevant to the prevention and control of PM pollution and the planning and construction of urban forests and grasslands. The effect of vegetation on PM reduction is a complex process, but there are many other factors that have more or less influence on this process, in addition to the parameters already considered. Therefore, there is still much room for improvement in the methods used to quantify the effect of vegetation on PM reduction. As people become increasingly aware of the important role of vegetation in improving environmental quality, relevant in-depth research will be performed and the methods will be optimized and refined continuously to more accurately quantify the effects of vegetation on reducing PM.

\section{Conclusions}

On the scale of entire cities and built-up areas, the reduction effect of forestland, grassland and urban green space on PM in the BTH area was calculated, and the reduced amount of vegetation on PM was quantified according to different regions, different times and different vegetation types. The results confirmed that the self-purification function of forestland and grassland played important roles in reducing and controlling PM concentrations, providing a scientific reference and theoretical basis for better exploiting the ecological and environmental benefits of vegetation. The following main conclusions were drawn.

(1) The reduction in $\mathrm{PM}_{10}$ by vegetation was approximately 30 times that of $\mathrm{PM}_{2.5}$. However, the reduction in $\mathrm{PM}_{2.5}$ by vegetation should not be ignored because $\mathrm{PM}_{2.5}$ has a stronger correlation with human production and living activities. The total amounts of $\mathrm{PM}_{10}$ reduced by forestland and grassland in the BTH area were 505,200 $\mathrm{t}$ 465,500 $t, 477,200 t$ and 396,500 $t$ in 2015, 2016, 2017 and 2018, respectively, and the concentrations of $\mathrm{PM}_{10}$ were reduced by $0.454 \mu \mathrm{g} \cdot \mathrm{m}^{-3}, 0.417 \mu \mathrm{g} \cdot \mathrm{m}^{-3}, 0.429 \mu \mathrm{g} \cdot \mathrm{m}^{-3}$ 
and $0.429 \mu \mathrm{g} \cdot \mathrm{m}^{-3}$, respectively, per hour. The total amount of $\mathrm{PM}_{2.5}$ was reduced by $19,400 \mathrm{t}, 19,200 \mathrm{t}, 16,400 \mathrm{t}$ and 12,700 $\mathrm{t}$ in 2015, 2016, 2017 and 2018, respectively, and the concentration of $\mathrm{PM}_{2.5}$ was reduced by $0.017 \mu \mathrm{g} \cdot \mathrm{m}^{-3}, 0.017 \mu \mathrm{g} \cdot \mathrm{m}^{-3}, 0.015 \mu \mathrm{g} \cdot \mathrm{m}^{-3}$ and $0.011 \mu \mathrm{g}^{-3}$ per hour, respectively.

(2) The reduction amount, concentration reduction value and concentration improvement rate of vegetation for $\mathrm{PM}_{10}$ were significantly higher than those for $\mathrm{PM}_{2.5}$. However, because $\mathrm{PM}_{2.5}$ has a stronger correlation with human production and living activities, the reduction effect of vegetation on $\mathrm{PM}_{2.5}$ cannot be ignored. More than $80 \%$ of the reduction in annual yield was concentrated in May-September, and a large leaf area was the main reason for the largest yield reduction in the growing season. The efficiency of PM reduction in forestland was approximately five-seven times that in grassland, and DBF was the main driver of PM reduction in each forest. Reducing and controlling the concentration of PM by increasing the area and density of green space to create an environment suitable for dry sedimentation and giving full play to the functional effect of green space ecosystems are very important.

The reduction effect of vegetation on PM is a continuous, dynamic process. Dry deposition per unit time occurs under the combined action of temperature, humidity, wind speed, precipitation, PM concentration, leaf shape and many other environmental conditions. Future research will be more integrated with actual measurements and better analyses, incorporating the influence of more environmental factors into experiments. In addition, given that human emissions are one of the important causes of excessive PM concentrations, future research will more comprehensively explore its relationship with vegetation reduction.

Author Contributions: J.Y. is the corresponding author. H.Z. contributed to improving the methodology and wrote the manuscript. X.T. helped edit and improve the manuscript. G.W. contributed to testing the methodology. All authors have read and agreed to the published version of the manuscript.

Funding: This work was supported by grants from the Chinese postdoctoral science foundation (No. 2021M693782).

Conflicts of Interest: The authors declare no conflict of interest.

\section{References}

1. Churg, A.; Brauer, M.; del Carmen Avila-Casado, M.; Fortoul, T.I.; Wright, J.L. Chronic exposure to high levels of particulate air pollution and small airway remodeling. Environ. Health Perspect. 2003, 111, 714-718. [CrossRef] [PubMed]

2. Hoek, G.; Krishnan, R.M.; Beelen, R.; Peters, A.; Ostro, B.; Brunekreef, B.; Kaufman, J.D. Long-term air pollution exposure and cardio-respiratory mortality: A review. Environ. Health 2013, 12, 43. [CrossRef] [PubMed]

3. Cao, J. Major causes and control strategies of the $\mathrm{PM}_{2.5}$ pollution in China. Sci. Technol. Rev. 2016, 34, 74-80.

4. $\quad$ Butlin, R.N.; Coote, A.T.; Devenish, M.; Hughes, I.S.C.; Hutchens, C.M.; Irwin, J.G.; Lloyd, G.O.; Massey, S.W.; Webb, A.H.; Yates, T.J.S. Preliminary results from the analysis of metal samples from the National Materials Exposure Programme (NMEP). Atmos. Environment. Part B. Urban Atmos. 1992, 26, 199-206. [CrossRef]

5. Zhang, X.-Y. Aerosol over China and Their Climate Effect. Adv. Earth Sci. 2007, 22, 12-16.

6. Lu, F.; Xu, D.; Cheng, Y.; Dong, S.; Guo, C.; Jiang, X.; Zheng, X. Systematic review and meta-analysis of the adverse health effects of ambient $\mathrm{PM}_{2.5}$ and $\mathrm{PM}_{10}$ pollution in the Chinese population. Environ. Research. Sect. A 2015, 136, 196-204. [CrossRef] [PubMed]

7. Maleki, H.; Sorooshian, A.; Goudarzi, G.; Nikfal, A.; Baneshi, M.M. Temporal profile of $\mathrm{PM}_{10}$ and associated health effects in one of the most polluted cities of the world (Ahvaz, Iran) between 2009 and 2014. Aeolian Res. 2016, 22, 135-140. [CrossRef]

8. Janssen, N.A.; Hoek, G.; Simic-Lawson, M.; Fischer, P.; Van Bree, L.; Ten Brink, H.; Cassee, F.R. Black carbon as an additional indicator of the adverse health effects of airborne particles compared with $\mathrm{PM}_{10}$ and $\mathrm{PM}_{2.5}$. Environ. Health Perspect. 2011, 119, 1691-1699. [CrossRef]

9. Lou, C.; Liu, H.; Li, Y.; Li, Y. Research on the response of air particles $\left(\mathrm{PM}_{2.5}, \mathrm{PM}_{10}\right)$ to landscape structure: A review. Acta Ecol. Sin. 2016, 36, 6719-6729.

10. Nguyen, T.; Yu, X.; Zhang, Z.; Liu, M.; Liu, X. Relationship between types of urban forest and $\mathrm{PM}_{2.5}$ capture at three growth stages of leaves. J. Environ. Sci. 2015, 27, 33-41. [CrossRef] [PubMed]

11. Tallis, M.; Taylor, G.; Sinnett, D.; Freer-Smith, P. Estimating the removal of atmospheric particulate pollution by the urban tree canopy of London, under current and future environments. Landsc. Urban Plan. 2011, 103, 129-138. [CrossRef] 
12. Yi, X.-Y.; Peng, Y.-H.; Liao, J.-Y.; Liu, Y.; Li, G.-F. A review of the relationship between forest vegetation and atmospheric particulate matter. Plant Sci. J. 2017, 35, 156-162.

13. Xie, L.; Huang, F.; Gan, X.; Wen, X.; Huang, Y. Research progress on the purification effects of urban forest vegetation on atmospheric particulate pollution matter. For. Environ. Sci. 2017, 33, 96-103.

14. Ma, K.; Yin, Z.; Zhang, Y. Advancement in the method and mechanism of the green space dust retention effect. Acta Ecol. Sin. 2018, 38, 391-400

15. Wu, H.; Yu, X.; Shi, C.; Zhang, Y.; Zhang, Z. Advances in the study of $\mathrm{PM}_{2.5}$ characteristic and the regulation of forests to $\mathrm{PM}_{2.5}$ Sci. Soil Water Conserv. 2012, 10, 116-122.

16. Cao, H.; Yin, S.; Zhang, X.; Xiong, F.; Zhu, P.; Liu, C. Modeled PM 2.5 removal by urban forest in Shanghai. J. Shanghai Jiaotong Univ. Agric. Sci. 2016, 34, 76-83.

17. Xiao, Y.; Wang, S.; Li, N.; Xie, G.; Lu, C.; Zhang, B.; Zhang, C. Atmospheric $\mathrm{PM}_{2.5}$ removal by green spaces in Beijing. Resour. Sci. 2015, 37, 1149-1155.

18. Nowak, D.J.; Hirabayashi, S.; Doyle, M.; McGovern, M.; Pasher, J. Air pollution removal by urban forests in Canada and its effect on air quality and human health. Urban For. Urban Green. 2018, 29, 40-48. [CrossRef]

19. Nowak, D.J.; Crane, D.E.; Stevens, J.C. Air pollution removal by urban trees and shrubs in the United States. Urban For. Urban Green. 2006, 4, 115-123. [CrossRef]

20. Al-Dousari, A.M.; Alsaleh, A.; Ahmed, M.; Misak, R.; William, T. Off-road vehicle tracks and grazing points in relation to soil compaction and land degradation. Earth Syst. Environ. 2019, 3, 471-482. [CrossRef]

21. Abd El-Wahab, R.H.; Al-Rashed, A.R.; Al-Dousari, A. Influences of physiographic factors, vegetation patterns and human impacts on aeolian landforms in arid environment. Arid. Ecosyst. 2018, 8, 97-110. [CrossRef]

22. Escobedo, F.J.; Nowak, D.J. Spatial heterogeneity and air pollution removal by an urban forest. Landsc. Urban Plan. 2009, 90, 102-110. [CrossRef]

23. Vos, P.E.J.; Maiheu, B.; Vankerkom, J.; Janssen, S. Improving local air quality in cities: To tree or not to tree? Environ. Pollut. 2013, 183, 113-122. [CrossRef] [PubMed]

24. Zhang, X.; Jiao, D.; Huang, T.; Zhagn, L.; Gao, H.; Zhao, Y.; Ma, J. Atmospheric removal of PM 2.5 by man-made Three Northern Regions Shelter Forest in Northern China estimated using satellite retrieved $\mathrm{PM}_{2.5}$ concentration. Sci. Total Environ. 2017, 593-594, 713-721. [CrossRef] [PubMed]

25. Al-Dousari, A.; Pye, K.; Alhazza, A.; Al-Shati, F.; Rajab, M. Nanosize inclusions as a fingerprint for aeolian sediments. J. Nanoparticle Res. 2020, 22, 94. [CrossRef]

26. Al-Dousari, A.; Ibrahim, M.I.; Al-Dousari, N.; Ahmed, M.; Awadhi, S.A. Pollen in aeolian dust with relation to allergy and asthma in Kuwait. Aerobiologia 2018, 34, 325-336. [CrossRef]

27. Nowak, D.J.; Crane, D.E. The Urban Forest Effects (UFORE) model: Quantifying urban forest structure and functions. Integr. Tools Proc. 2000, 212, 714-720.

28. Chen, J.M.; Black, T.A. Defining leaf area index for non-flat leaves. Agric. For. Meteorol. 1992, 15, 421-429. [CrossRef]

29. Gower, S.T.; Kucharik, C.J.; Norman, J.M. Direct and indirect estimation of leaf area index, fAPAR, and net primary production of terrestrial ecosystems. Remote Sens. Environ. 1999, 70, 29-51. [CrossRef]

30. Lovett, G.M. Atmospheric deposition of nutrients and pollutants in North America: An ecological perspective. Ecol. Appl. 1994, 4, 630-650. [CrossRef]

31. Zinke, P.J. Forest interception studies in the United States. In Forest Hydrology; Sopper, W.E., Lull, H.W., Eds.; Pergamon Press: Oxford, UK, 1967; pp. 137-161.

32. Hirabayashi, S.; Kroll, C.N.; Nowak, D.J. i-Tree Eco Dry Deposition Model Descriptions. Available online: https:/ /www.itreetools. org/documents/60/iTree_Eco_Dry_Deposition_Model_Descriptions.pdf (accessed on 27 February 2015).

33. Tiwary, A.; Sinnett, D.; Peachey, C.; Chalabi, Z.; Vardoulakis, S.; Fletcher, T.; Leonardi, G.; Grundy, C.; Azapagic, A.; Hutchings, T.R. An integrated tool to assess the role of new planting in $\mathrm{PM}_{10}$ capture and the human health benefits: A case study in London. Environ. Pollut. 2009, 157, 2645-2653. [CrossRef]

34. Baldocchi, D.D.; Hicks, B.B.; Camara, P. A canopy stomatal resistance model for gaseous deposition to vegetated surfaces. Atmos. Environ. 1987, 21, 91-101. [CrossRef]

35. Yang, J.; Mcbride, J.; Zhou, J.; Sun, Z. The urban forest in Beijing and its role in air pollution reduction. Urban For. Urban Green. 2005, 3, 65-78. [CrossRef]

36. Nowak, D.J.; Crane, D.E.; Stevens, J.C.; Hoehn, R.E.; Walton, J.T.; Bond, J. A ground-based method of assessing urban forest structure and ecosystem services. Arboric. Urban For. 2008, 34, 347-358. [CrossRef]

37. Freer-Smith, P.H.; Elkhatib, A.A.; Taylor, G. Capture of particulate pollution by trees: A comparison of species typical of semi-arid areas (ficus nitida and eucalyptus globulus) with European and North American Species. Water Air Soil Pollut. 2004, 155, 173-187. [CrossRef]

38. Beckett, K.P.; Freer-Smith, P.H.; Taylor, G. Particulate pollution capture by urban trees: Effect of species and windspeed. Glob. Change Biol. 2000, 6, 995-1003. [CrossRef]

39. Pullman, M.R. Conifer PM 2.5 Deposition and Re-Suspension in Wind and Rain Events; Cornell University: New York, NY, USA, 2009.

40. Shreffler, J.H. Factors affecting dry deposition of $\mathrm{SO}_{2}$ on forests and grasslands. Atmos. Environ. 1978, 12, 1497-1503. [CrossRef] 
41. Escobedo, F.J.; Wagner, J.E.; Nowak, D.J.; Maza, C.L.D.L.; Rodriguez, M.; Crane, D.E. Analyzing the cost effectiveness of Santiago, Chile's policy of using urban forests to improve air quality. J. Environ. Manag. 2008, 86, 148-157. [CrossRef] [PubMed]

42. Fowler, D.; Skiba, U.; Nemitz, E.; Choubedar, F.; Branford, D.; Donovan, R.; Rowland, P. Measuring aerosol and heavy metal deposition on urban woodland and grass using inventories of $210 \mathrm{~Pb}$ and metal concentrations in soil. Water Air Soil Pollut. Focus 2004, 4, 483-499. [CrossRef]

43. Mcdonald, A.G.; Bealey, W.J.; Fowler, D.; Dragosits, U.; Skiba, U.; Smith, R.I.; Donovan, R.G.; Brett, H.E.; Hewitt, C.N.; Nemitz, E. Quantifying the effect of urban tree planting on concentrations and depositions of PM in two UK conurbations. Atmos. Environ. 2007, 41, 8455-8467. [CrossRef]

44. Zhao, H.; Che, H.; Xia, X.; Wang, Y.; Wang, H.; Wang, P.; Ma, Y.; Yang, H.; Liu, Y.; Wang, Y.; et al. Climatology of mixing layer height in China based on multi-year meteorological data from 2000 to 2013. Atmos. Environ. 2019, 213, 90-103. [CrossRef]

45. Wang, J.; Endreny, T.A.; Nowak, D.J. Mechanistic simulation of tree effects in an urban water balance model. Jawra J. Am. Water Resour. Assoc. 2010, 44, 75-85. [CrossRef]

46. Jiang, L.; Zhou, H.; Lai, Z.; Bai, L.; Chen, Z. Analysis of spatio-temporal characteristic of PM 2.5 concentrations of Chinese cities: 2015-2017. Acta Sci. Circumstantiae 2018, 38, 3816-3825.

47. Nowak, D.J.; Hirabayashi, S.; Bodine, A.; Hoehn, R. Modeled $\mathrm{PM}_{2.5}$ removal by trees in ten U.S. cities and associated health effects. Environ. Pollut. 2013, 178, 395-402. [CrossRef] [PubMed]

48. Conte, M.; Donateo, A.; Contini, D. Characterisation of particle size distributions and corresponding size-segregated turbulent fluxes simultaneously with $\mathrm{CO}_{2}$ exchange in an urban area. Sci. Total Environ. 2018, 622-623, 1067-1078. [CrossRef] [PubMed]

49. Casquero-Vera, J.A.; Lyamani, H.; Titos, G.; Moreira, G.d.A.; Benavent-Oltra, J.A.; Conte, M.; Continid, D.; Järvie, L.; Olmo-Reyes, F.J.; Alados-Arboledas, L. Aerosol number fluxes and concentrations over a southern European urban area. Atmos. Environ. 2022, 269, 118849. [CrossRef]

50. Scott, K.I.; McPherson, E.G.; Simpson, J.R. Air pollutant uptake by Sacramento's urban forest. J. Arboric. 1998, 24, $224-234$.

51. Chang, Y.M. Analysis of $P M_{2.5}$ Removal by New Plantations in the Beijing Plain Area; Beijing Forestry University: Beijing, China, 2015.

52. Chen, L.; Liu, C.-L.; Pan, T.; Chen, C.-C.; Li, Z.; Wang, H.-H.; Pei, S.; Sun, L. Assessment of the effect of PM 2.5 reduction by plain afforestation project in Beijing based on dry deposition model. Chin. J. Ecol. 2014, 33, 2897-2904. 